Frame contained PDF file, click here to view

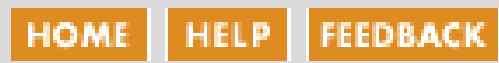 \\ SUBSCRIPTIONS ARCHIVE SEARCH \\ TABLE OF CONTENTS
}

\section{This Article}

PDF version of:

Goonasekera et al. 130 (4): 365 . (2007)

Abstract FREE

Full Text (HTML)

Alert me when this article is cited

Article usage stats

Citation Map

\section{Services}

Email this article

Alert me to new content in the J GP

Download to citation manager

\section{Citing Articles}

Citing Articles via CrossRef

Google Scholar

Articles by Goonasekera, S. A.

Articles by Dirksen, R. T.

\section{PubMed}

\section{PubMed Citation}

Articles by Goonasekera, S. A.

Articles by Dirksen, R. T.

\section{Social Bookmarking}

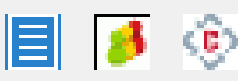

What's this?

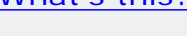

\section{Help}


Adobe Acrobat plugin users:

View article in full window

\section{Printing problems?}

To print a PDF using the Acrobat plugin, use the printer button in the plugin's toolbar, located immediately above the document.

\section{Download Adobe Reader}

\section{Institution: AUSTRALI N NATL} UNI V | Sign In via User Name/

Password 


\title{
Triadin Binding to the C-Terminal Luminal Loop of the Ryanodine Receptor is Important for Skeletal Muscle Excitation-Contraction Coupling
}

\author{
Sanjeewa A. Goonasekera, ${ }^{1}$ Nicole A. Beard, ${ }^{2}$ Linda Groom, ${ }^{1}$ Takashi Kimura, ${ }^{2}$ Alla D. Lyfenko, ${ }^{1}$ \\ Andrew Rosenfeld, ${ }^{1}$ Isabelle Marty, ${ }^{3}$ Angela F. Dulhunty, ${ }^{2}$ and Robert T. Dirksen ${ }^{1}$ \\ 1Department of Pharmacology and Physiology, University of Rochester, Rochester, NY 14642 \\ ${ }^{2}$ Division of Molecular Bioscience, John Curtin School of Medical Research, Australian National University, P.O. Box 334, Canberra, \\ ACT, 2601, Australia \\ 3INSERM U607; CEA Grenoble, DRDC, F38054 Grenoble cedex, France
}

\begin{abstract}
$\mathrm{Ca}^{2+}$ release from intracellular stores is controlled by complex interactions between multiple proteins. Triadin is a transmembrane glycoprotein of the junctional sarcoplasmic reticulum of striated muscle that interacts with both calsequestrin and the type 1 ryanodine receptor (RyR1) to communicate changes in luminal $\mathrm{Ca}^{2+}$ to the release machinery. However, the potential impact of the triadin association with RyR1 in skeletal muscle excitation-contraction coupling remains elusive. Here we show that triadin binding to RyR1 is critically important for rapid $\mathrm{Ca}^{2+}$ release during excitation-contraction coupling. To assess the functional impact of the triadin-RyR1 interaction, we expressed RyR1 mutants in which one or more of three negatively charged residues (D4878, D4907, and E4908) in the terminal RyR1 intraluminal loop were mutated to alanines in RyR1-null (dyspedic) myotubes. Coimmunoprecipitation revealed that triadin, but not junctin, binding to RyR1 was abolished in the triple (D4878A/D4907A/ E4908A) mutant and one of the double (D4907A/E4908A) mutants, partially reduced in the D4878A/D4907A double mutant, but not affected by either individual (D4878A, D4907A, E4908A) mutations or the D4878A/E4908A double mutation. Functional studies revealed that the rate of voltage- and ligand-gated $\mathrm{SR} \mathrm{Ca}^{2+}$ release were reduced in proportion to the degree of interruption in triadin binding. Ryanodine binding, single channel recording, and calcium release experiments conducted on WT and triple mutant channels in the absence of triadin demonstrated that the luminal loop mutations do not directly alter RyR1 function. These findings demonstrate that junctin and triadin bind to different sites on RyR1 and that triadin plays an important role in ensuring rapid $\mathrm{Ca}^{2+}$ release during excitation-contraction coupling in skeletal muscle.
\end{abstract}

\section{INTRODUCTION}

$\mathrm{Ca}^{2+}$ signaling in most cells depends on $\mathrm{Ca}^{2+}$ release from intracellular stores. The efficiency of $\mathrm{Ca}^{2+}$ release is determined by the $\mathrm{Ca}^{2+}$ binding capacity of the store proteins and the activity of $\mathrm{Ca}^{2+}$ release channels in the store membrane. The $\mathrm{Ca}^{2+}$ store in striated muscle, the SR, plays a central role in the vital functions of movement, respiration, and heart beat (Rossi and Dirksen, 2006). The key $\mathrm{Ca}^{2+}$ binding protein in the SR is calsequestrin (CSQ) and the $\mathrm{Ca}^{2+}$ release channel is the ryanodine receptor (RyR) (Zhang et al., 1997; Beard et al., 2004). CSQ not only binds $\mathrm{Ca}^{2+}$ but also regulates $\mathrm{Ca}^{2+}$ release by communicating with the RyR via two intermediary proteins, triadin and junctin (Beard et al., 2002; Gyorke et al., 2004; Wei et al., 2006), which are found in many tissues and play a ubiquitous role in $\mathrm{Ca}^{2+}$ signaling. Both are transmembrane proteins that bind to CSQ and the RyR (Jones et al., 1995) to form a CSQ triadin/junctin/RyR "luminal $\mathrm{Ca}^{2+}$ transduction machine"

S.A. Goonasekera and N.A. Beard contributed equally to this work. Correspondence to Robert T. Dirksen: Robert_Dirksen@URMC. Rochester.edu that is central to $\mathrm{Ca}^{2+}$ release unit function (Beard et al., 2002, 2004; Gyorke et al., 2004; Wei et al., 2006) and assembly (Tijskens et al., 2003).

Triadin is a junctional SR protein discovered in 1990 by Brandt et al. (1990) that was originally proposed to play a critical role in excitation-contraction (EC) coupling (Kim et al., 1990). However, since the bulk of the protein is located within the SR lumen where it binds to CSQ and the RyR (Knudson et al., 1993b; Guo and Campbell, 1995), it is currently believed to facilitate cross-talk between CSQ and the RyR (Beard et al., 2002), rather than directly influence EC coupling (Gyorke et al., 2004). Junctin was later discovered and thought to have a comparable function to triadin, due to its similar structure and ability to also bind CSQ and the RyR (Jones et al., 1995; Zhang et al., 1997; Tijskens et al., 2003). The specific residues in RyR1 that bind triadin and junctin are functionally relevant and, therefore, of

Abbreviations used in this paper: 4-cmc, 4-chloro-m-cresol; CSQ, calsequestrin; DHPR, dihydropyridine receptor; EC, excitation-contraction; RyR1, ryanodine receptor type-1; WT, wild type. 
great interest. A putative triadin binding site was recently identified in the terminal intraluminal loop of RyR1 between residues 4860 and 4917 (Lee et al., 2004). More recently, alanine substitution of three specific negatively charged residues within this region (D4878, D4907, and E4908) was found to disrupt triadin binding to fulllength RyR1 and also alter the magnitude and kinetics of caffeine-induced $\mathrm{Ca}^{2+}$ release (Lee et al., 2006). However, the relative impact of disrupting the triadin-RyR1 interaction on $\mathrm{Ca}^{2+}$ release during EC coupling, potential direct effects of the mutations on RyR1 function that are unrelated to triadin binding, or effects of the mutations on junctin binding to RyR1 have not been investigated.

Here we demonstrate that the intraluminal RyR1 residues D4878, D4907, and E4908 contribute unequally $(\mathrm{D} 4907>\mathrm{E} 4908>\mathrm{D} 4878)$ to triadin binding to RyR1 and that this interaction is an important regulator of both voltage- and ligand-induced $\mathrm{SR} \mathrm{Ca}^{2+}$ release in skeletal muscle. Moreover, we found that disruption of triadin binding to RyR1 did not affect junctional targeting of RyR1, RyR1 enhancement of dihydropyridine receptor (DHPR) calcium channel activity (retrograde coupling; see Dirksen, 2002 for review), or the ability of junctin to bind to RyR1. We propose a model whereby triadin binding to RyR1 enhances release channel opening in response to both voltage- and ligand-induced activation and that this activity is important for ensuring robust and rapid calcium release during EC coupling.

\section{MATERIALS AND METHODS}

\section{Preparation of Mutants and Nuclear Microinjection} of Dyspedic Myotubes

The D4878A $\left(\Delta \mathrm{M}_{1}\right), \mathrm{D} 4907 \mathrm{~A}\left(\Delta \mathrm{M}_{2}\right), \mathrm{E} 4908 \mathrm{~A}\left(\Delta \mathrm{M}_{3}\right), \mathrm{D} 4878 \mathrm{~A} /$ D4907A $\left(\Delta \mathrm{M}_{1,2}\right), \mathrm{D} 4878 \mathrm{~A} / \mathrm{E} 4908 \mathrm{~A}\left(\Delta \mathrm{M}_{1,3}\right), \mathrm{D} 4907 \mathrm{~A} / \mathrm{E} 4908 \mathrm{~A}$ $\left(\Delta \mathrm{M}_{2,3}\right)$, and $\mathrm{D} 4878 \mathrm{~A} / \mathrm{D} 4907 \mathrm{~A} / \mathrm{E} 4908 \mathrm{~A}\left(\Delta \mathrm{M}_{1,2,3}\right)$ mutations were introduced into a full-length rabbit RyR1 cDNA using standard two-step site-directed mutagenesis. All sequences generated and modified by PCR were checked for integrity by sequence analysis. Primary cultures of dyspedic myotubes were cultured from skeletal myoblasts isolated from newborn dyspedic mice (Nakai et al., 1996; Avila et al., 2001). After allowing myoblasts to differentiate into multinucleated myotubes for 4-7 d, nuclei of individual myotubes were microinjected with cDNAs encoding CD8 $(0.1 \mu \mathrm{g} / \mu \mathrm{l})$ and one of the RyR1 constructs at a concentration of $0.5 \mu \mathrm{g} / \mu \mathrm{l}$. Expressing myotubes were subsequently identified 48-72 h after injection by incubation with CD8 antibody-coated beads (Dynabeads, Dynal ASA). All animals were anaesthetized and humanely killed following procedures that were reviewed and approved by the University Committee on Animals Resources at the University of Rochester School of Medicine and Dentistry.

\section{Measurements of Electrically Evoked and Agonist-induced $\mathrm{Ca}^{2+}$ Transients in Myotubes}

Intracellular $\mathrm{Ca}^{2+}$ measurements in intact myotubes were obtained from Indo-1 AM (TefLabs Inc.) loaded myotubes (Avila et al., 2001). Cytosolic dye within a rectangular region of the cell was excited at $350 \mathrm{~nm}$ and fluorescence emission at 405 and $485 \mathrm{~nm}$ was measured at $100 \mathrm{~Hz}$ sampling frequency using a $40 \times$ oil objective, a photomultiplier detection system (Photon Technology
International), and results are presented as the ratio of 405 and $485 \mathrm{~nm}\left(\mathrm{~F}_{405} / \mathrm{F}_{485}\right)$. These $\mathrm{Ca}^{2+}$ measurements were conducted in a normal rodent Ringer's solution consisting of (in $\mathrm{mM}$ ) 145 $\mathrm{NaCl}, 5 \mathrm{KCl}, 2 \mathrm{CaCl}_{2}, 1 \mathrm{MgCl}_{2}, 10$ HEPES, pH 7.4. Electrically evoked $\mathrm{Ca}^{2+}$ transients were elicited using field stimulation $(8 \mathrm{~V}$, $20 \mathrm{~ms}$ ) applied every $10 \mathrm{~s}$. A caffeine $(30 \mathrm{mM})$ or 4-chloro-mcresol (4-cmc, $500 \mu \mathrm{M}$ ) bolus was delivered at the end of the protocol to assess release channel expression and $\mathrm{SR} \mathrm{Ca}^{2+}$ content. Data are presented as mean \pm SEM with significance accepted at $\mathrm{P}<0.01$ (unpaired Student's $t$ test).

\section{Simultaneous Measurements of Macroscopic $\mathrm{Ca}^{2+}$ Currents} and Transients in Myotubes

Whole-cell patch clamp experiments were used to simultaneously measure voltage-gated L-type $\mathrm{Ca}^{2+}$ currents and $\mathrm{Ca}^{2+}$ transients (Avila et al., 2001). Peak L-current magnitude was normalized to cell capacitance $(\mathrm{pA} / \mathrm{pF})$ and plotted as a function of membrane potential $\left(\mathrm{V}_{\mathrm{m}}\right)$ and fitted according to

$$
\mathrm{I}=\mathrm{G}_{\mathrm{max}}\left(\mathrm{V}_{\mathrm{m}}-\mathrm{V}_{\mathrm{rev}}\right) /\left(1+\exp \left[\left(\mathrm{V}_{\mathrm{Gl} / 2}-\mathrm{V}_{\mathrm{m}}\right) / \mathrm{k}_{\mathrm{G}}\right]\right),
$$

where $G_{\max }$ is the maximal L-channel conductance, $V_{m}$ is test potential, $\mathrm{V}_{\text {rev }}$ is extrapolated reversal potential, $\mathrm{V}_{\mathrm{G} 1 / 2}$ is the voltage for half-maximal activation of $\mathrm{G}_{\max }$, and $\mathrm{k}_{\mathrm{G}}$ is a slope factor. Relative changes in intracellular $\mathrm{Ca}^{2+}$ in these experiments were measured after dialysis with $\mathrm{K}_{5}$-Fluo-4 salt. Relative changes in Fluo-4 fluorescence $(\Delta \mathrm{F} / \mathrm{F})$ were measured either 30 or $200 \mathrm{~ms}$ after depolarization, plotted as a function of $\mathrm{V}_{\mathrm{m}}$, and fitted according to

$$
\Delta \mathrm{F} / \mathrm{F}=\left(\Delta \mathrm{F} / \mathrm{F}_{\max }\right) /\left\{1+\exp \left[\left(\mathrm{V}_{\mathrm{Fl} / 2}-\mathrm{V}_{\mathrm{m}}\right) / \mathrm{k}_{\mathrm{F}}\right]\right\},
$$

where $(\Delta \mathrm{F} / \mathrm{F})_{\max }$ is the calculated maximal change in fluorescence, $\mathrm{V}_{\mathrm{F} 1 / 2}$ is the voltage for half-maximal activation of $(\Delta \mathrm{F} / \mathrm{F})_{\max }$, and $\mathrm{k}_{\mathrm{F}}$ is a slope factor. The bell-shaped voltage dependence of $\Delta \mathrm{F} / \mathrm{F}$ measurements obtained in $\Delta \mathrm{M}_{1,2,3^{-}}$and $\Delta \mathrm{M}_{2,3}$-expressing myotubes was fitted according to the following equation:

$\Delta \mathrm{F} / \mathrm{F}=\left((\Delta \mathrm{F} / \mathrm{F})_{\max }\left(\left(\mathrm{V}_{\mathrm{m}}-\mathrm{V}_{\text {rev }}\right) / \mathrm{k}^{\prime}\right)\right) /\left(1+\exp \left(\left(\mathrm{V}_{\mathrm{Fl} / 2}-\mathrm{V}_{\mathrm{m}}\right) / \mathrm{k}_{\mathrm{F}}\right)\right)$,

where $(\Delta \mathrm{F} / \mathrm{F})_{\max }, \mathrm{V}_{\mathrm{m}}, \mathrm{V}_{\mathrm{rev}}, \mathrm{V}_{\mathrm{F} 1 / 2}$, and $\mathrm{k}_{\mathrm{F}}$ have their usual meanings. The additional variable $\mathrm{k}^{\prime}$ is a scaling factor that varies with $(\Delta \mathrm{F} / \mathrm{F})_{\max }$ (Sheridan et al., 2003; Goonasekera et al., 2005). Pooled current-voltage $(\mathrm{I}-\mathrm{V})$ and fluorescence-voltage $(\Delta \mathrm{F} / \mathrm{F}-\mathrm{V})$ data in Table I are expressed as mean \pm SEM. All patch clamp experiments were conducted in an external solution consisting of (in mM) 145 TEA-Cl, $10 \mathrm{CaCl}_{2}$, and 10 HEPES (pH 7.4). The internal patch pipette solution consisted of (in mM) 145 CsAspartate, $10 \mathrm{CsCl}, 0.1 \mathrm{Cs}_{2}$-EGTA, $1.2 \mathrm{MgCl}_{2}, 5 \mathrm{Mg}$-ATP, $0.2 \mathrm{~K}_{5-}$ Fluo-4, and 10 HEPES (pH 7.4).

\section{Measurements of 4-cmc-induced $\mathrm{Ca}^{2+}$ Transients in HEK293 Cells}

HEK293 cells plated on coverslips were transfected with either WT RyR1 or $\Delta \mathrm{M}_{1,2,3}$ cDNA (Jiang et al., 2002). $2 \mathrm{~d}$ after transfection, cells were loaded with $5 \mu \mathrm{M}$ Fura-2 AM for 30 min at $37^{\circ} \mathrm{C}$ in Ringer's solution. Coverslips of Fura-2-loaded cells were then mounted in a tissue chamber on the stage of an epifluorescenceequipped inverted microscope. Cells were sequentially excited at 340- and 380-nm wavelength and fluorescence emission at $510 \mathrm{nM}$ was collected using a high-speed IMAGO-QE CCD camera (TILL Photonics). The results are presented as the ratio of $\mathrm{F}_{340} / \mathrm{F}_{380}$ (collected at $6.25 \mathrm{~Hz}$ ). Maximal increase in intracellular $\mathrm{Ca}^{2+}$ induced by addition of 4-cmc $(500 \mu \mathrm{M})$ was defined as the difference between peak and baseline fluorescence ratios during agonist exposure. 
Purification of Triadin and Junctin

Triadin and junctin were purified from rabbit skeletal muscle as previously described (Mulvey and Ohlendieck, 2003) except that after separation by electrophoresis, proteins were eluted by gentle agitation at $37^{\circ} \mathrm{C}$ in a buffer containing $0.5 \%$ CHAPS,

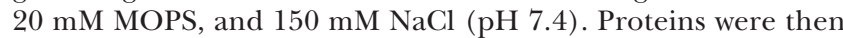
dialyzed twice against $20 \mathrm{mM}$ MOPS, $150 \mathrm{mM} \mathrm{NaCl}, \mathrm{pH}$ 7.4. Purification was enhanced by immunoselection with anti-junctin or anti-triadin.

\section{$\left[{ }^{3} \mathrm{H}\right]$ Ryanodine Binding and Single Channel Recording} of Purified RyRs

WT and $\Delta \mathrm{M}_{1,2,3}$ RyR1 constructs were expressed and purified from HEK293 cells as previously described (Kimura et al., 2005; Kimura et al., 2007). $\left[{ }^{3} \mathrm{H}\right]$ Ryanodine binding was performed as previously described (Kimura et al., 2005), except that $5 \mathrm{mg}$ of purified RyR1 protein was used in all experiments and in some experiments preincubation with triadin $(5 \mu \mathrm{g} / \mathrm{ml})$ was done for $30 \mathrm{~min}$ on ice, before initiating $\left[{ }^{3} \mathrm{H}\right]$ Ryanodine binding. Single channel experiments were conducted as described in (Kimura et al., 2005), using the following conditions. To incorporate purified RyRs (WT or $\Delta \mathrm{M}_{1,2,3}$ ), the standard incorporation solution consisted of the following: cis: $230 \mathrm{mM}$ Cs-methanesulfonate, $20 \mathrm{mM}$ $\mathrm{CsCl}, 5 \mathrm{mM} \mathrm{CaCl}$, and $10 \mathrm{mM}$ TES (pH 7.4); and trans: $30 \mathrm{mM}$ Cs-methanesulfonate, $20 \mathrm{mM} \mathrm{CsCl}, 1 \mathrm{mM} \mathrm{CaCl}_{2}$, and $10 \mathrm{mM}$ TES (pH 7.4). Immediately after channel incorporation, $200 \mathrm{mM}$ Cs-methanesulfonate was added to the trans chamber (to ensure recording solution symmetry) and cis $\mathrm{Ca}^{2+}$ was adjusted to $1 \mathrm{mM}$, $10 \mu \mathrm{M}$, or $100 \mathrm{nM}$ by the addition of $\mathrm{Ca}^{2+}$ chelator (BAPTA). Channel activity was analyzed over 10-30-s periods of continuous activity at +40 and $-40 \mathrm{mV}$. Slow fluctuations in the baseline were corrected using an in-house program written by Dr. D.R. Laver. Channel activity was measured either as "mean current" (average of all data points) or as open probability $\left(\mathrm{P}_{\mathrm{o}}\right)$, using threshold analysis with the program Channel 2, (developed by Drs. P.W. Gage and M. Smith, JCSMR). Measurements of mean current, performed on 30-s records from bilayers containing one to four channels, included all channel activity from small subconductance openings to maximum levels. Mean current divided by the maximum current provides an approximate measure of $\mathrm{P}_{\mathrm{o}}$. $\mathrm{P}_{\mathrm{o}}$, mean open times $\left(\mathrm{T}_{\mathrm{o}}\right)$, and mean closed times $\left(\mathrm{T}_{\mathrm{c}}\right)$ were measured directly during periods of recording in which the opening of only a single channel was detected. Threshold levels for channel opening and closing were set at $\sim 20 \%$ of the maximum single channel conductance in order to exclude baseline noise.

\section{Immunoprecipitations}

Precleared purified skeletal muscle triadin or junctin were incubated with either anti-triadin or anti-junctin antibody coupled to protein $\mathrm{A} / \mathrm{G}$ sepharose and incubated with purified recombinant RyR1s (expressed in HEK293 cells) for $2 \mathrm{~h}$ at $4^{\circ} \mathrm{C}$ in a buffer containing $20 \mathrm{mM}$ MOPS, $150 \mathrm{mM} \mathrm{NaCl}, \mathrm{pH}$ 7.4. Immunoprecipitates were washed three times in $20 \mathrm{mM}$ MOPS, $150 \mathrm{mM} \mathrm{NaCl}$ ( $\mathrm{pH}$ 7.4), proteins eluted from the beads by boiling for 2-3 min in Laemmli sample buffer, and subjected to SDS-PAGE and immunoblot. Identical results were obtained using similar buffers containing $1 \mathrm{mM} \mathrm{Ca}^{2+}$. Reverse immunoprecipitation was performed, using a sepharose/anti-RyR/RyR complex to assess binding of purified triadin and junctin to immobilized RyRs. Anti-RyR was obtained from Sigma-Aldrich. Each immunoprecipitation was repeated at least three times $(n \geq 3)$. Where appropriate, percent binding was calculated from three separate immunoprecipitates via immunoblot image analysis using the Genetools analysis software.

\section{Immunofluorescence Labeling}

Expressing dyspedic myotubes plated on glass coverslips were fixed and immunostained with a mouse monoclonal anti-RyR

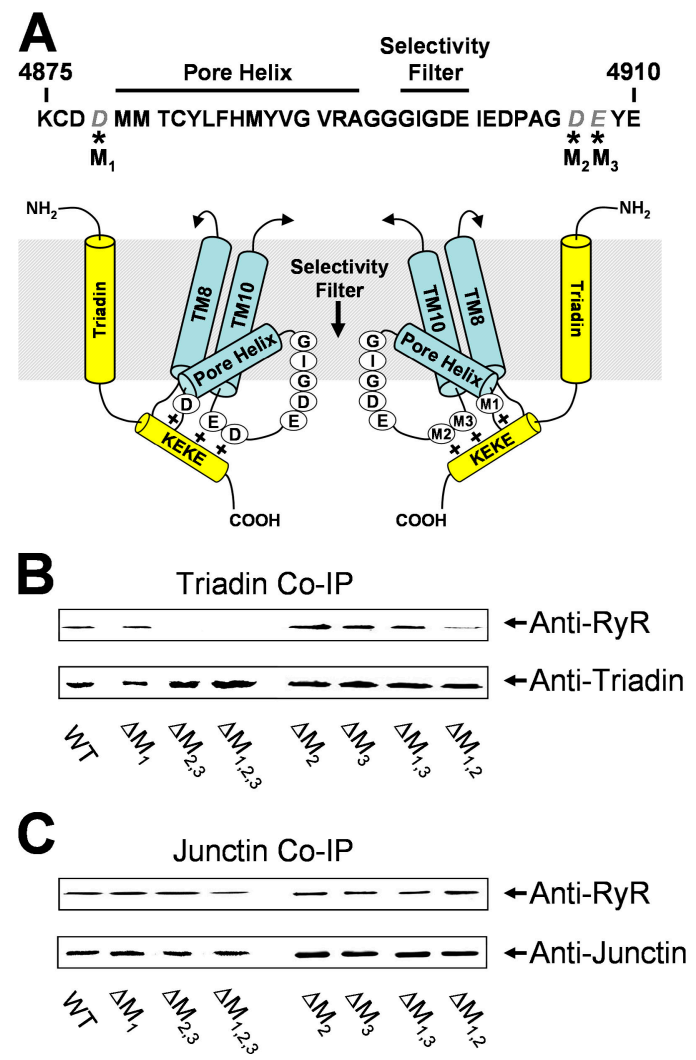

Figure 1. Triadin and junctin binding to RyR1 luminal loop mutants. (A) Proposed interaction between triadin and the terminal RyR1 luminal loop. (Top) Amino acid sequence for a portion of the luminal loop between the final two transmembrane domains of the rabbit RyR1 protein. Negatively charged amino acids mutated in this study (D4878, D4807, and E4809 on the left and $\mathrm{M}_{1}, \mathrm{M}_{2}$, and $\mathrm{M}_{3}$ on the right in the schematic) are shown in italics. (Bottom) Representation of the triadin interaction with the terminal luminal loop of RyR1 is modified from Fig. 5 of Lee et al. (2004). (B and C) Western blot analysis of proteins immunoprecipitated with anti-triadin (B) or anti-junctin (C). After incubation of the WT or mutant RyR1 (listed at the bottom of the blot) with either triadin (B) or junctin (C). Immunoprecipitations were performed and the immunoprecipitated protein analyzed by Western Blot using anti-RyR and anti-triadin (B) or anti-junctin (C).

antibody (34C, 1:10; Developmental Studies Hybridoma Bank) and a sheep polyclonal anti-DHPR antibody (1:200; Upstate Biotechnology) overnight at $4^{\circ} \mathrm{C}$ as previously described (Graves and Hinkle, 2003). On the following day, coverslips were washed with PBS three times each for 5 min and then incubated for $1 \mathrm{~h}$ at room temperature in blocking buffer containing a 1:500 dilution of Alexa Fluor 488-labeled donkey anti-mouse IgG (Molecular Probes) and 1:500 dilution of rhodamine-labeled donkey anti-sheep IgG (Jackson ImmunoResearch Laboratories Inc.) and washed with PBS (three times for 5 min each). Coverslips were mounted on glass slides and images obtained using a Nikon Eclipse-C1 confocal microscope (Nikon Instruments Inc.) and a $40 \times$ oil objective. All confocal images were sampled at a spatial resolution (pixel diameter) of $100 \mathrm{~nm}$. A similar protocol was used to immunostain and obtain images from WT RyR1- and $\Delta \mathrm{M}_{1,2,3}$-expressing HEK293 cells using antibody $34 \mathrm{C}(1: 20)$ and a rhodamine-conjugated goat anti-mouse $\operatorname{IgG}(1: 2,000)$. 


\section{RESULTS}

Three Negatively Charged Residues in the C-terminal Intraluminal Loop of RyR1 Unequally Coordinate

Triadin Binding

To determine the relative importance of the three negatively charged RyR1 residues identified by Lee et al. (2004) (Fig. 1 A) for triadin and junctin binding to fulllength RyR1, we assessed the effects of a comprehensive series of mutations to these residues in triadin and junctin coimmunoprecipitation. Purified skeletal triadin or junctin were coupled to protein $\mathrm{A} / \mathrm{G}$ sepharose via antitriadin or anti-junctin antibodies (respectively), and association with WT and mutated RyR1 constructs was determined by incubation with purified recombinant RyR1 constructs. In contrast to Lee et al. (2004), triadin binding to RyR1 was not altered by any of the single mutants (D4878A, $\Delta \mathrm{M}_{1} ; \mathrm{D} 4907 \mathrm{~A}, \Delta \mathrm{M}_{2} ; \mathrm{E} 4908 \mathrm{~A}, \Delta \mathrm{M}_{3}$ ) or for D4878A/E4908A $\left(\Delta \mathrm{M}_{1,3}\right)$ (Fig. $\left.1 \mathrm{~B}\right)$, with similar amounts of each mutant binding to triadin as that observed for WT RyR1. However, a $50 \% \pm 12 \%(n=3)$ reduction in triadin binding was observed for D4878A/D4907A $\left(\Delta \mathrm{M}_{1,2}\right)$ while triadin binding to D4907A/E4908A $\left(\Delta \mathrm{M}_{2,3}\right)$ and D4878A/D4907A/E4908A $\left(\Delta \mathrm{M}_{1,2,3}\right)$ was undetectable (Fig. $1 \mathrm{~B}$ ). Identical results were obtained in the absence of calcium (as in Lee et al., 2004) and in the presence of $1 \mathrm{mM} \mathrm{Ca}^{2+}$. In addition, identical results were also observed in reverse coimmunoprecipitation experiments in which purified WT RyR1 or $\Delta \mathrm{M}_{1,2,3}$ were coupled to protein A/G sepharose via anti-RyR and their ability to pull down purified triadin and junctin was detected (unpublished data). In marked contrast to triadin, none of the luminal loop mutations significantly altered the ability of RyR1 to interact with junctin (Fig. 1 G) since the amount of each RyR1 mutant construct associated with junctin was similar to that of WT RyR1.

Our results in Fig. 1 were not influenced by the use of purified proteins. In initial experiments, solubilized SR was used as a source of triadin to pull down WT or $\Delta \mathrm{M}_{1,2,3} \mathrm{RyR} 1$. The $\mathrm{SR}$ was exposed to $10 \mathrm{mM} \mathrm{Ca}^{2+}$ to inhibit the interaction between CSQ and either triadin or junctin (Beard et al., 2005) and to minimize interactions between triadin and junctin (Zhang et al., 1997), before exposure to anti-triadin protein $\mathrm{A} / \mathrm{G}$ sepharose. We found that exposure to $10 \mathrm{mM} \mathrm{Ca}^{2+}$ also dissociated triadin from the RyR. When the $\mathrm{Ca}^{2+}$ concentration was lowered appropriately, the anti-triadin/native triadin complex pulled down WT RyR1, but not $\Delta \mathrm{M}_{1,2,3}$ RyR1, as was observed using purified triadin in Fig. 1. Interestingly, in the light of experiments reported by Lee et al. (2006), we also performed experiments using anti-triadin antibody to pull down triadin from solubilized SR vesicles isolated from adult rabbit SR with either 0 or $1 \mathrm{mM}$ $\mathrm{Ca}^{2+}$ and found that the anti-triadin antibody pulled down a suite of proteins that included the RyR, triadin, CSQ, junctin, histidine-rich protein, and several other unidentified proteins.

The Triadin Binding-deficient RyR1 Mutant $\left(\Delta \mathrm{M}_{1,2,3}\right)$ Lacks Electrically Evoked $\mathrm{Ca}^{2+}$ Release and Exhibits Slowed Kinetics of Agonist-induced $\mathrm{Ca}^{2+}$ Release

To determine the consequences of disrupting triadin binding to RyR1 on skeletal muscle EC coupling, we expressed either WT RyR1 or $\Delta \mathrm{M}_{1,2,3}$ in myotubes derived from RyR1-null (dyspedic) mice. Extracellular electrical stimulation (Fig. 2 A, closed triangles) evoked robust and rapid global $\mathrm{Ca}^{2+}$ transients in intact Indo-1 AMloaded WT RyR1-expressing myotubes (Fig. 2 A, left),
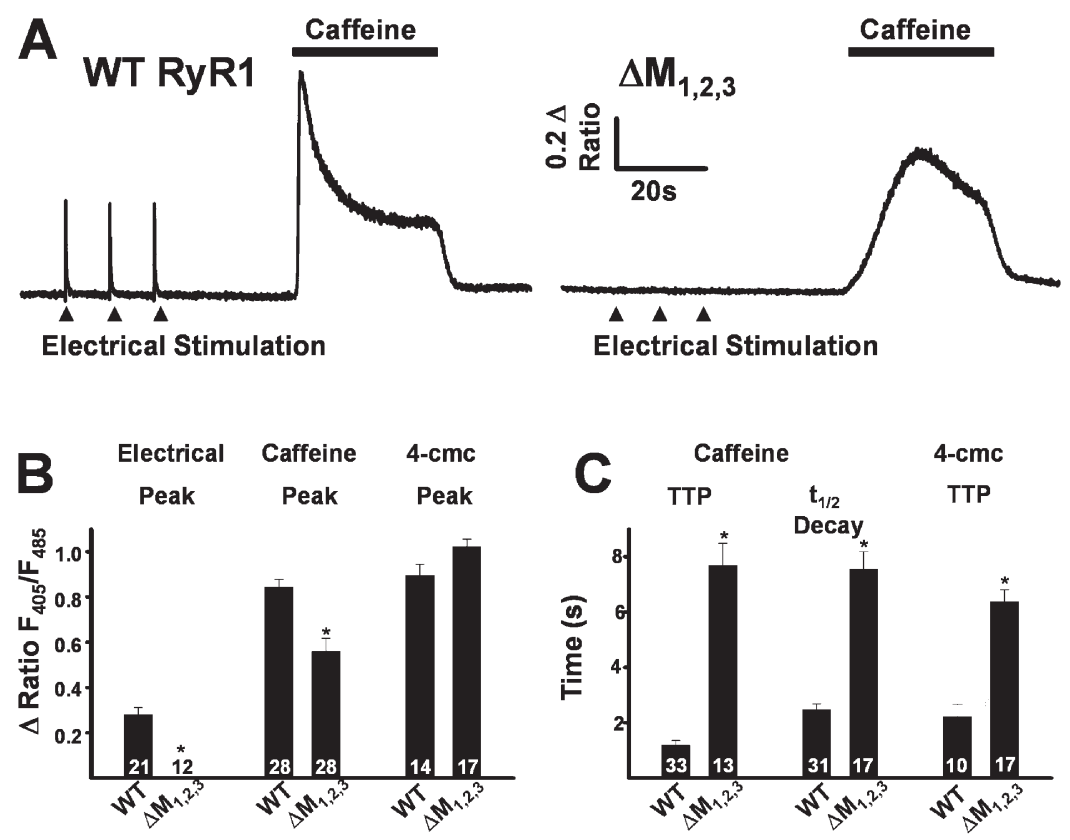

Figure 2. Effects of $\Delta \mathrm{M}_{1,2,3}$ on ligand-induced $\mathrm{Ca}^{2+}$ release. (A) Representative indo-1 ratio traces obtained from intact dyspedic myotubes expressing either WT RyR1 (left) or $\Delta \mathrm{M}_{1,2,3}$ (right) following electrical stimulation (filled triangles) and caffeine application (horizontal bars). (B) Average maximal magnitude of electrically evoked (left), caffeine-induced (middle), and 4-cmc-induced (right) $\mathrm{Ca}^{2+}$ release. (C) Average time to peak (TTP, left) and $t_{1 / 2}$ of decay (middle) for caffeineinduced $\mathrm{Ca}^{2+}$ release and time to peak $4-\mathrm{cmc} \mathrm{Ca}^{2+}$ release (TTP, right). *, $\mathrm{P}<0.01$. 

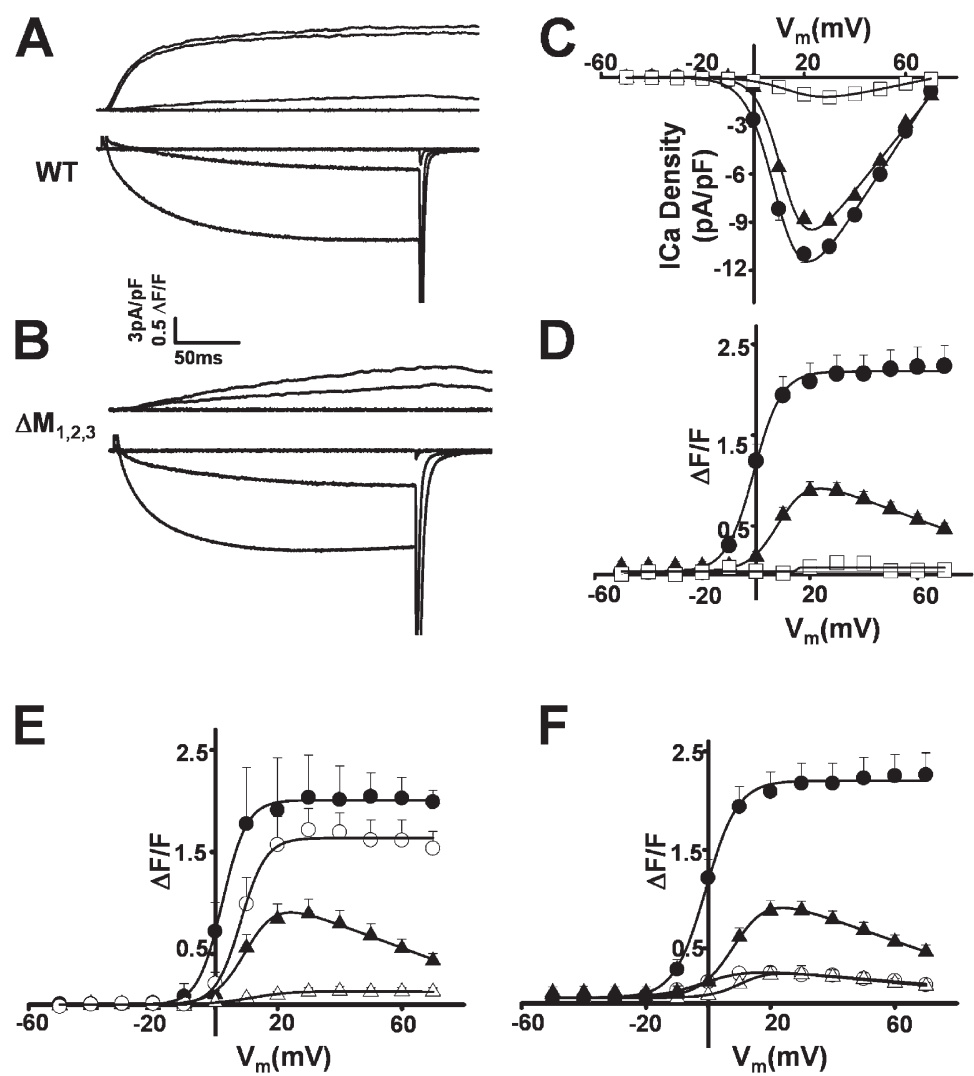

Figure 3. Effects of $\Delta \mathrm{M}_{1,2,3}$ on orthograde and retrograde DHPR-RyR1 coupling. (A) Representative L-type $\mathrm{Ca}^{2+}$ currents (bottom traces) and intracellular $\mathrm{Ca}^{2+}$ transients (top traces) resulting from 200-ms depolarizations to $-50,-10,+30$, and $+70 \mathrm{mV}$ in a WT RyR1expressing myotube. (B) Representative L-type $\mathrm{Ca}^{2+}$ currents (bottom traces) and intracellular $\mathrm{Ca}^{2+}$ transients (top traces) resulting from 200-ms depolarizations to $-50,-10,+30$, and $+70 \mathrm{mV}$ in a $\Delta \mathrm{M}_{1,2,3}$-expressing myotube. (C and D) Average voltage dependence of peak L-type $\mathrm{Ca}^{2+}$ current density (C) and intracellular $\mathrm{Ca}^{2+}$ transients (D) in naive dyspedic myotubes (open squares), WT RyR1-expressing (closed circles), and $\Delta \mathrm{M}_{1,2,3}$-expressing (closed triangles) myotubes. (E) Inhibition of L-type $\mathrm{Ca}^{2+}$ currents (with $0.5 \mathrm{mM} \mathrm{Cd}{ }^{2+} / 0.2 \mathrm{mM} \mathrm{La}^{3+}$, open symbols) markedly reduced ( $86 \pm 7 \%, n=5$ at $+30 \mathrm{mV})$ $\mathrm{Ca}^{2+}$ transients in $\Delta \mathrm{M}_{1,2,3}$-expressing myotubes (triangles) but only minimally reduced $(16 \pm 9 \%, n=5$ at $+30 \mathrm{mV})$ $\mathrm{Ca}^{2+}$ transients in WT RyR1-expressing myotubes (circles). (F) Blockade of $\mathrm{Ca}^{2+}$ release with $100 \mu \mathrm{M}$ ryanodine (open symbols) markedly reduced depolarization-induced $\mathrm{Ca}^{2+}$ transients in both WT RyR1- (circles) and $\Delta \mathrm{M}_{1,2,3^{-}}$ expressing (triangles) myotubes.

but not in uninjected (naive) dyspedic myotubes (unpublished data). However, while average resting Indo-1 ratios were not significantly different (resting $\mathrm{F}_{405} / \mathrm{F}_{485}$ was $0.60 \pm 0.01, n=28$, and $0.56 \pm 0.01, n=27$, for WT RyR1- and $\Delta \mathrm{M}_{1,2,3}$-expressing myotubes, respectively), $\Delta \mathrm{M}_{1,2,3}$-expressing myotubes lacked electrically evoked $\mathrm{Ca}^{2+}$ transients (Fig. $2 \mathrm{~A}$, right, and Fig. $2 \mathrm{~B}$ ). To confirm functional $\Delta \mathrm{M}_{1,2,3}$ expression, a maximal concentration $(30 \mathrm{mM})$ of caffeine or $4-\mathrm{cmc}(500 \mu \mathrm{M})$ was applied to both WT- and $\Delta \mathrm{M}_{1,2,3}$-expressing myotubes (Fig. 2, $\mathrm{A}$ and $\mathrm{B}) . \mathrm{Ca}^{2+}$ release in response to caffeine was reduced in $\Delta \mathrm{M}_{1,2,3}$-expressing myotubes (Fig. $2 \mathrm{~B}$ ) and the kinetics of caffeine-induced and 4-cmc-induced $\mathrm{Ca}^{2+}$ release (time to peak and $t_{1 / 2}$ of decay) were significantly slowed (Fig. 2, A and C).

\section{The Triadin Binding-deficient RyR1 Mutant $\left(\Delta \mathrm{M}_{1,2,3}\right)$ Supports Retrograde, but not Orthograde, DHPR-RyR1 Coupling}

Simultaneous whole-cell patch clamp measurements of voltage-gated L-type $\mathrm{Ca}^{2+}$ currents and intracellular $\mathrm{Ca}^{2+}$ transients were used to determine the ability of the $\Delta \mathrm{M}_{1,2,3}$ triadin binding-deficient mutant to support the retrograde and orthograde signals of skeletal muscle EC coupling (Fig. $3 \mathrm{~A}$ ). Naive dyspedic myotubes exhibited small $(<1 \mathrm{pA} / \mathrm{pF})$ L-type $\mathrm{Ca}^{2+}$ currents (Fig. $3 \mathrm{C}$, open squares) and lacked voltage-gated $\mathrm{Ca}^{2+}$ release (Fig. 3 D, open squares) (Nakai et al., 1996). Expression of WT RyR1 (Fig. $3 \mathrm{~A})$ restored robust $(\sim 10 \mathrm{pA} / \mathrm{pF})$ voltage-gated L-type $\mathrm{Ca}^{2+}$ currents (bottom traces) and $\mathrm{Ca}^{2+}$ transients (top traces). Interestingly, while expression of $\Delta \mathrm{M}_{1,2,3}$ (Fig. $3 \mathrm{~B}$ ) similarly enhanced L-type $\mathrm{Ca}^{2+}$ current density, $\mathrm{Ca}^{2+}$ release was markedly slower and reduced in magnitude. Voltage-gated $\mathrm{Ca}^{2+}$ transients in WT RyR1-expressing myotubes exhibited the characteristic sigmoidal voltage dependence of skeletal muscle EC coupling (Fig. 3 D, filled circles), while $\mathrm{Ca}^{2+}$ transients in $\Delta \mathrm{M}_{1,2,3}$-expressing myotubes exhibited a bell-shaped voltage dependence (Fig. $3 \mathrm{D}$, filled triangles) that mirrored that of the L-type $\mathrm{Ca}^{2+}$ current (Fig. $3 \mathrm{C}$, filled triangles). The bell-shaped $\mathrm{Ca}^{2+}$ transients in $\Delta \mathrm{M}_{1,2,3}-\mathrm{ex}-$ pressing myotubes largely arose from $\mathrm{Ca}^{2+}$ influx-induced $\mathrm{Ca}^{2+}$ release through $\Delta \mathrm{M}_{1,2,3}$ channels as they were markedly reduced by blockers of both the L-type $\mathrm{Ca}^{2+}$ channel $\left(0.5 \mathrm{mM} \mathrm{Cd}^{2+}+0.2 \mathrm{mM} \mathrm{La}^{3+}\right.$, open symbols in

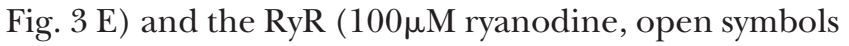
in Fig. $3 \mathrm{~F}$ ).

\section{RyR1 Mutations that Disrupt Triadin Binding Do Not}

\section{Directly Alter Release Channel Function}

The observed alterations in ligand and voltage-gated $\mathrm{Ca}^{2+}$ release in $\Delta \mathrm{M}_{1,2,3}$-expressing dyspedic myotubes documented in Figs. 2 and 3 could either be due to effects of the mutations on triadin regulation of RyR1 or to direct effects of the mutations on channel function that are independent of triadin binding. To test for potential direct effects of the mutations, we compared the subcellular localization and function of WT and $\Delta \mathrm{M}_{1,2,3}$ RyR1 

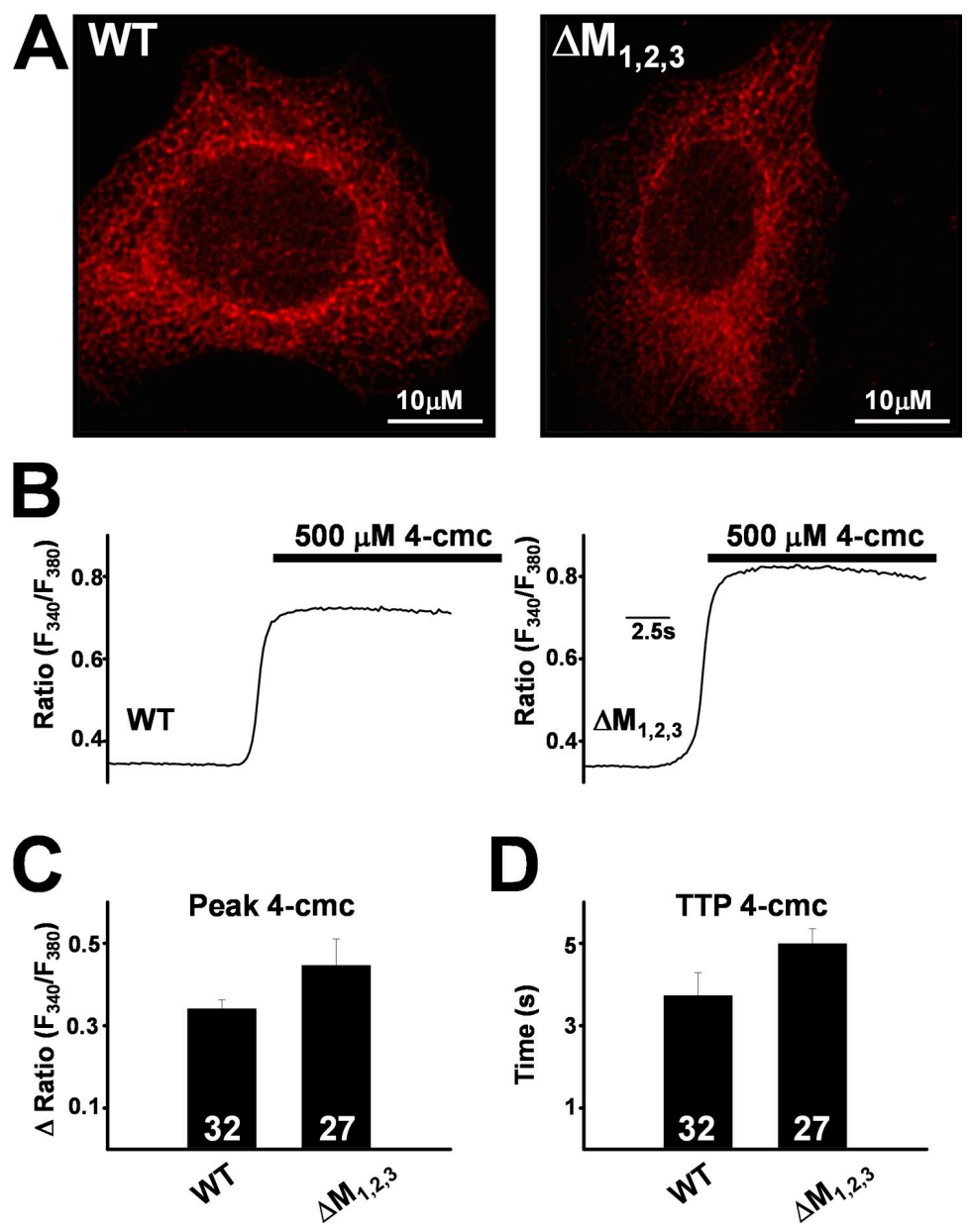

channels following expression in HEK293 cells (Figs. 4 and 5). WT and $\Delta \mathrm{M}_{1,2,3}$ channels exhibited identical reticulated ER localization (Fig. 4 A) following expression in HEK293 cells. Since HEK293 cells do not express triadin and 4-cmc activates $\mathrm{Ca}^{2+}$ release through expressed RyR1 channels (Fessenden et al., 2000), we compared 4 -cmc-induced $\mathrm{Ca}^{2+}$ release responses in WT- and $\Delta \mathrm{M}_{1,2,3-}$ expressing HEK293 cells. The magnitude and kinetics of 4-cmc-induced $\mathrm{Ca}^{2+}$ release was not significantly different $(\mathrm{P}>0.05)$ between WT- and $\Delta \mathrm{M}_{1,2,3}$-expressing HEK293 cells (Fig. 4, B-D).

We next compared the function of purified WT and $\Delta \mathrm{M}_{1,2,3}$ channels following expression in HEK293 cells (Fig. 5). WT and $\Delta \mathrm{M}_{1,2,3}$ channels exhibited identical $\mathrm{Ca}^{2+}$ dependence of $\left[{ }^{3} \mathrm{H}\right]$ ryanodine binding, with binding (which indirectly reflects $\mathrm{P}_{\mathrm{o}}$ ) increasing with channel activation between $100 \mathrm{nM}$ and $10 \mu \mathrm{M}$ cis $\mathrm{Ca}^{2+}\left(\mathrm{EC}_{50}\right.$ was $4.14 \pm 0.34$ and $3.99 \pm 0.17 \mu \mathrm{M}$ for WT and $\Delta \mathrm{M}_{1,2,3}$ channels, respectively) and then similarly declining as cis $\mathrm{Ca}^{2+}$ rises above $10 \mu \mathrm{M}$ (Fig. $5 \mathrm{~A}$ ). The data in Fig. $5 \mathrm{~A}$ are expressed relative to maximum binding in $10 \mu \mathrm{M} \mathrm{Ca}^{2+}$ in order to reduce variations between ER preparations. Maximal $\left[{ }^{3} \mathrm{H}\right]$ ryanodine binding was not significantly different between WT and $\Delta \mathrm{M}_{1,2,3}$ channels $\left(\mathrm{B}_{\max }\right.$ was $4.8 \pm 0.6$ and $4.5 \pm 0.1 \mathrm{pM} / \mathrm{mg}$ for WT and $\Delta \mathrm{M}_{1,2,3}$ channels, respectively). Preincubation of recombinant WT RyR1 channels with $5 \mu \mathrm{g} / \mathrm{ml}$ triadin increased $\left[{ }^{3} \mathrm{H}\right]$ ryanodine binding relative to binding in the absence of triadin. In contrast, incubation with triadin had no effect on maximal $\left[{ }^{3} \mathrm{H}\right]$ ryanodine binding to $\Delta \mathrm{M}_{1,2,3}$ RyR1 (Fig. 5 B). These results demonstrate a strong functional consequence of triadin binding to WT RyR 1 and the lack of any functional change when triadin is added to triadin binding-deficient $\Delta \mathrm{M}_{1,2,3}$ channels. Previous studies have shown an inhibitory interaction between the cytoplasmic domain of triadin and RyR1 (Ohkura et al., 1998; Groh et al., 1999).

The activity of single $\Delta \mathrm{M}_{1,2,3}$ channels in bilayers was similar to that of WT channels (Fig. 5, C-J). In six of eight experiments using either $\mathrm{WT}$ or $\Delta \mathrm{M}_{1,2,3}$ channels, current recordings showed periods where more than one channel opened in the bilayer with similar openings in WT and mutant channels (Fig. 5 C). To include data from these recordings, open probability of 30-s recordings was calculated as the mean current in the recording (average of all data points) normalized to the maximum current (maximum open level), i.e., $\mathrm{I}_{\text {mean }} / \mathrm{I}_{\max }$ (Fig. $5 \mathrm{D}$ ) (Beard et al., 2002). In each experiment, channel activity was initially recorded in $5 \mathrm{mM}$ cis $\mathrm{Ca}^{2+}$ to aid in channel incorporation, cis $\mathrm{Ca}^{2+}$ concentration was then decreased 

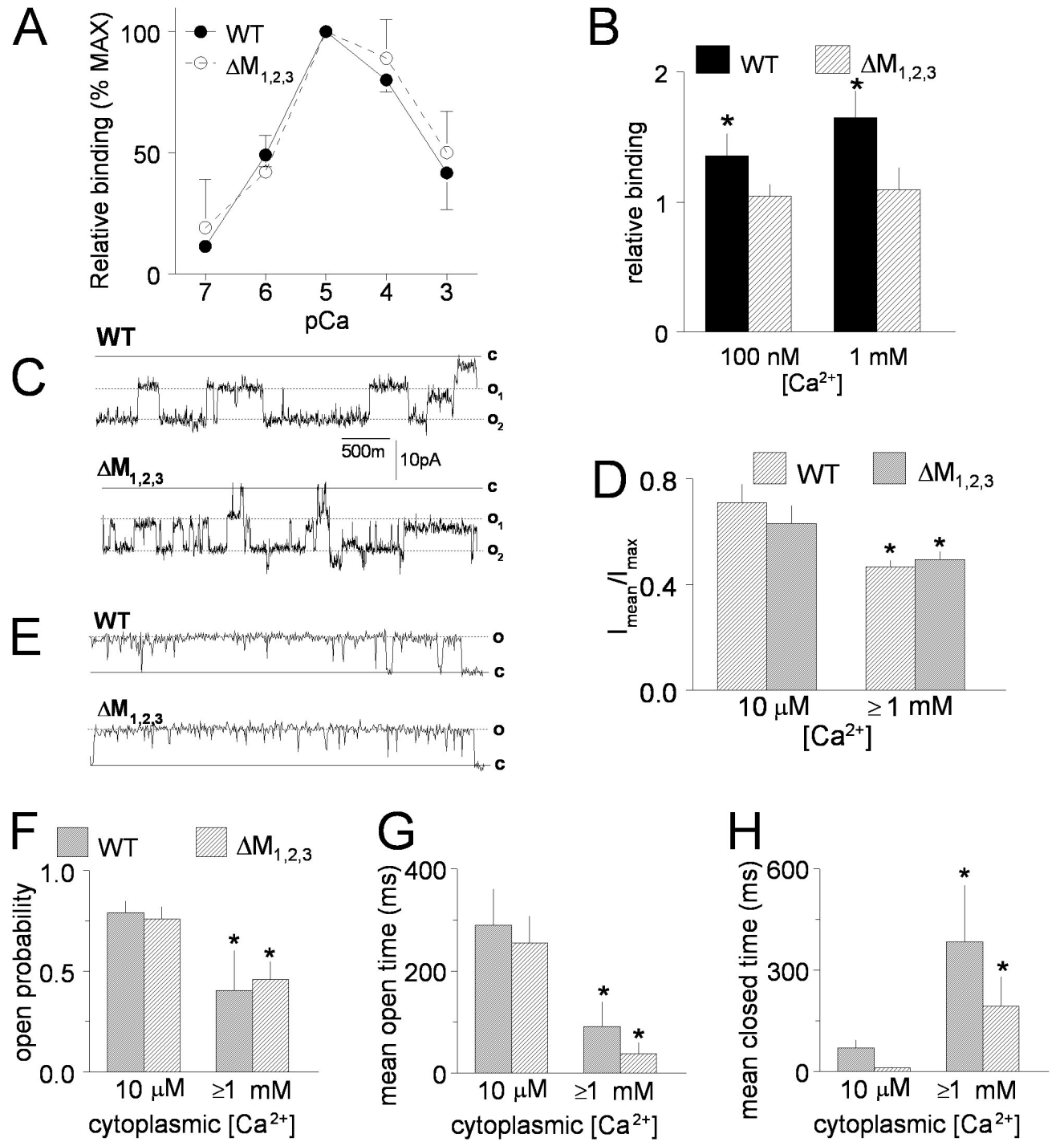

I

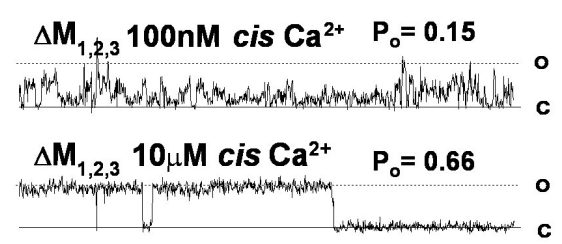

B
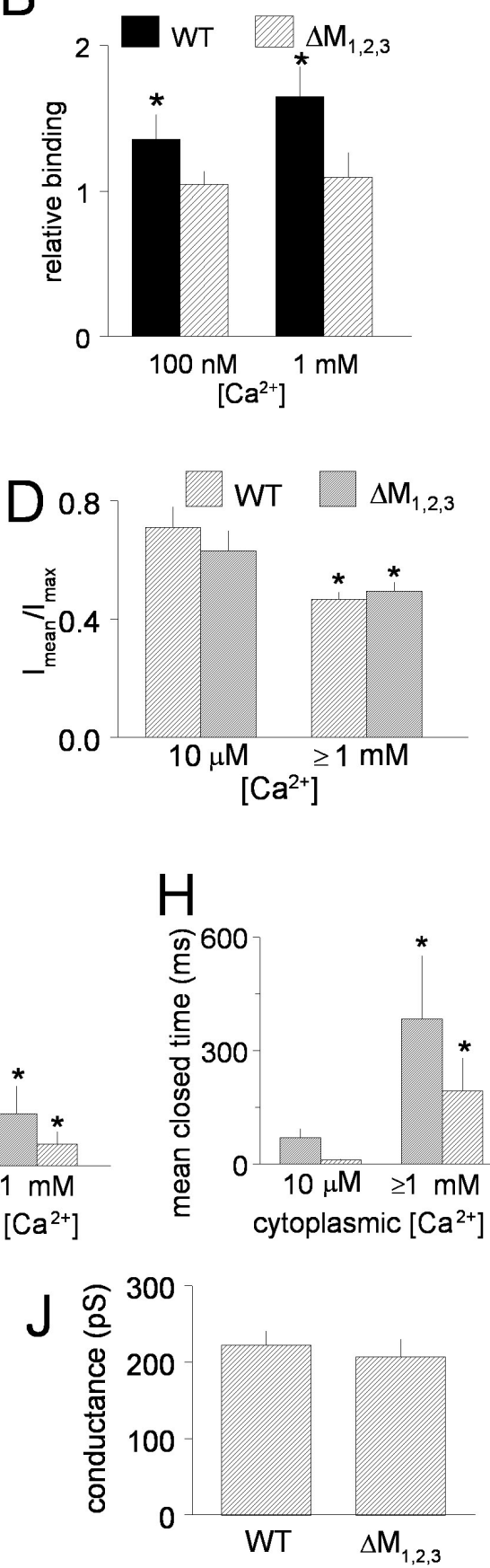

Figure 5. Properties of purified WT RyR1 and $\Delta \mathrm{M}_{1,2,3}$ channels expressed in HEK293 cells. (A) $\mathrm{Ca}^{2+}$ dependence of $\left[{ }^{3} \mathrm{H}\right]$ ryanodine binding $(\%$ maximum binding) to WT (closed circles) and $\Delta \mathrm{M}_{1,2,3}$ (closed squares) channels. (B) Effect of preincubation with $5 \mu \mathrm{g} / \mathrm{ml}$ purified triadin on $\left[{ }^{3} \mathrm{H}\right]$ ryanodine binding in the presence of either $100 \mathrm{nM}$ or $1 \mathrm{mM} \mathrm{Ca}^{2+}(n=$ 6 for each). *, $\mathrm{P}<0.05$. $\left[{ }^{3} \mathrm{H}\right]$ ryanodine binding to purified RyR1 in the presence of triadin (filled bars) is normalized to binding to purified RyR1 in absence of triadin (crosshatched bars). (C) Representative single channel records from artificial lipid bilayers incorporated with two purified WT (top) and two purified $\Delta \mathrm{M}_{1,2,3}$ (bottom) channels at $-40 \mathrm{mV}$ in the presence of $1 \mathrm{mM}$ trans (luminal) $\mathrm{Ca}^{2+}$ and $10 \mu \mathrm{M}$ cis (cytoplasmic) $\mathrm{Ca}^{2+}$. The channels opened from the closed level (c) to either single open $\left(\mathrm{o}_{1}\right)$ and double open $\left(\mathrm{O}_{2}\right)$ levels. (D) Average data from four WT RyR1 channels and four $\Delta \mathrm{M}_{1,2,3}$ channels showing open probability measured as mean current $\left(\mathrm{I}_{\text {mean }}\right)$ normalized to maximum current $\left(\mathrm{I}_{\max }\right)$ during periods in which only one or two channels were open in the bilayer. Open probability decreased when the cis $\mathrm{Ca}^{2+}$ was increased from $10 \mu \mathrm{M}$ to either $1 \mathrm{mM}$ or $5 \mathrm{mM}$ (data for 1 and $5 \mathrm{mM}$ cis $\mathrm{Ca}^{2+}$ at +40 and $-40 \mathrm{mV}$ were grouped in the average data). $*, \mathrm{P}<0.05$. (E) Periods of single channel activity in recordings from bilayers containing purified WT (top) and $\Delta \mathrm{M}_{1,2,3}$ (bottom) channels at $+40 \mathrm{mV}$

with $1 \mathrm{mM}$ trans (luminal) $\mathrm{Ca}^{2+}$ and $10 \mu \mathrm{M}$ cis (cytoplasmic) $\mathrm{Ca}^{2+}$. (F-H) Average open probability (F), mean open time $(\mathrm{G})$, and mean closed time $(\mathrm{H})$ for 30-s recordings from four WT and four $\Delta \mathrm{M}_{1,2,3}$ channels in the presence of $10 \mu \mathrm{M}$ cis $\mathrm{Ca}^{2+}$ and combined data for 1 and $5 \mathrm{mM}$ cis $\mathrm{Ca}^{2+}$. ${ }^{*}, \mathrm{P}<0.05$. (I) Data from a $\Delta \mathrm{M}_{1,2,3}$ channel recorded first in $100 \mathrm{nM}$ cis $\mathrm{Ca}^{2+}$ (top) and then in $10 \mu \mathrm{M}$ cis Ca ${ }^{2+}$ (bottom). The open probability for $30 \mathrm{~s}$ of channel activity at each $\mathrm{Ca}^{2+}$ concentration is given above each record. (J) Average single channel conductance from four WT RyR1 channels and four $\Delta \mathrm{M}_{1,2,3}$ RyR1 channels.

to $10 \mu \mathrm{M}$ and subsequently returned to $1 \mathrm{mM}$. Since there was no significant difference in channel activity between 1 or $5 \mathrm{mM}$ cis $\mathrm{Ca}^{2+}$, data at these two concentrations were combined and reported as $\geq 1 \mathrm{mM}$ in Fig. 5 (D-H). In agreement with the $\left[{ }^{3} \mathrm{H}\right]$ ryanodine binding data (Fig. 5 A) and previous studies (Laver et al., 1997), WT channel activity fell significantly when the cis $\mathrm{Ca}^{2+}$ concentration was increased from $10 \mu \mathrm{M}$ to $\geq 1 \mathrm{mM} \mathrm{Ca}^{2+}$. However, no significant difference was observed between WT and $\Delta \mathrm{M}_{1,2,3}$ channels (Fig. 5, D and F). All recordings showed periods (10-30 s) of single channel opening (Fig. $5 \mathrm{C}$ ) that were also analyzed for open probability, mean open time, and mean closed time using a standard $20 \%$ threshold-crossing criterion (see Materials and methods). 
A
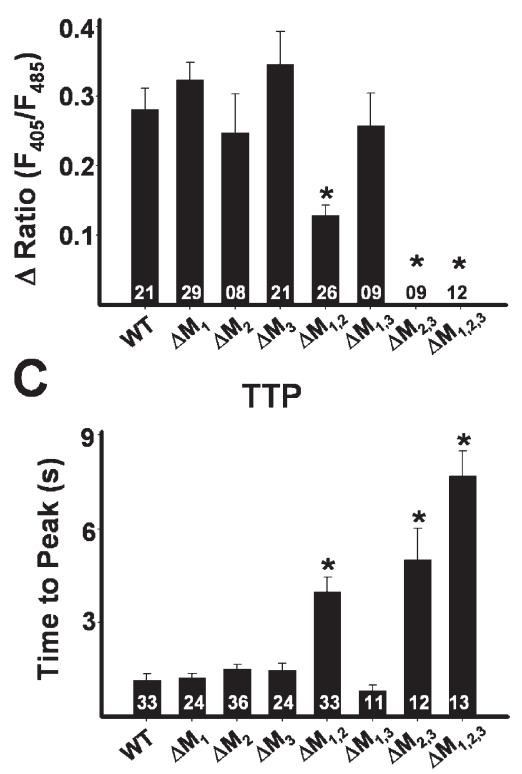

B
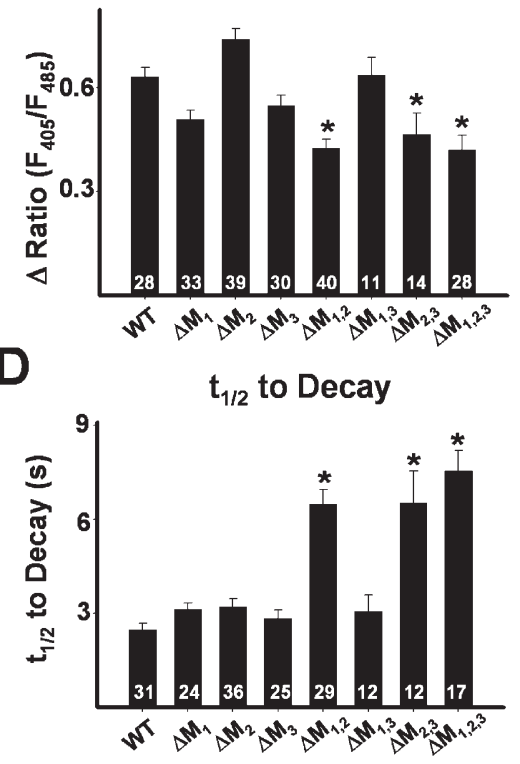

Figure 6. Effects of the terminal luminal loop RyR1 mutants on electrically evoked and caffeine-induced $\mathrm{Ca}^{2+}$ release. (A-D) Bar graphs summarizing the effects of each of WT RyR1 and the different terminal RyR1 luminal loop mutants $\left(\Delta \mathrm{M}_{1}, \Delta \mathrm{M}_{2}, \Delta \mathrm{M}_{3}\right.$, $\Delta \mathrm{M}_{1,2}, \Delta \mathrm{M}_{1,3}, \Delta \mathrm{M}_{2,3}$, and $\left.\Delta \mathrm{M}_{1,2,3}\right)$ on electrically evoked $\mathrm{Ca}^{2+}$ release (A), peak caffeineinduced $(30 \mathrm{mM}) \mathrm{Ca}^{2+}$ release $(\mathrm{B})$, and the average time to peak $(\mathrm{C})$ and $t_{1 / 2}$ of decay (D) of caffeine-induced $\mathrm{Ca}^{2+}$ transients.
Open probability values obtained with this method (Fig. $5 \mathrm{~F}$ ) were very similar to those estimated from $\mathrm{I}_{\text {mean }} / \mathrm{I}_{\max }$ (Fig. 5 D). The decline in open probability when cis $\mathrm{Ca}^{2+}$ concentration was increased from $10 \mu \mathrm{M}$ to $\geq 1 \mathrm{mM}$ was due to an abbreviation of the mean open time (Fig. $5 \mathrm{G}$ ) and prolongation of the mean closed time (Fig. $5 \mathrm{H}$ ). These changes in mean open and closed times were similar in WT and $\Delta \mathrm{M}_{1,2,3}$ channels.

In one experiment with a $\Delta \mathrm{M}_{1,2,3}$ channel, the cis $\mathrm{Ca}^{2+}$ concentration was lowered to $100 \mathrm{nM}$ and then increased to $10 \mu \mathrm{M}$ (Fig. $5 \mathrm{I}$ ). As expected from the $\left[{ }^{3} \mathrm{H}\right]$ ryanodine binding data (Fig. $5 \mathrm{~A}$ ), the open probability of this channel was greater with $10 \mu \mathrm{M}$ cis $\mathrm{Ca}^{2+}$ than with $100 \mathrm{nM}$ cis $\mathrm{Ca}^{2+}$, increasing from 0.15 to 0.66 ; the mean open time increased from 10.9 to $54.4 \mathrm{~ms}$, and the mean closed time fell from 58.3 to $27.4 \mathrm{~ms}$. The changes in open probability, mean open time, and mean closed time when $\mathrm{Ca}^{2+}$ concentration was increased from $100 \mathrm{nM}$ to $10 \mu \mathrm{M}$ in this $\Delta \mathrm{M}_{1,2,3}$ channel are similar to changes in the activity of WT channels that occur over the same range of $\mathrm{Ca}^{2+}$ concentrations. Finally, the $\Delta \mathrm{M}_{1,2,3}$ mutation did not significantly affect unitary conductance of RyR1 channels (Fig. $5 \mathrm{~J}$ ) and the conductance at $+40 \mathrm{mV}$ was similar to that at $-40 \mathrm{mV}$ (Fig. 5, compare $\mathrm{C}$ with $\mathrm{E}$ or I). Average $\mathrm{Cs}^{+}$conductance was $222 \pm 19 \mathrm{pS}$ for WT RyR1 and $207 \pm 24 \mathrm{pS}$ for $\Delta \mathrm{M}_{1,2,3}$. Taken together, the data in Figs. 4 and 5 demonstrate that WT and $\Delta \mathrm{M}_{1,2,3}$ channels exhibit similar channel function in the absence of triadin.

Effects of Other RyR1 Luminal Loop Mutations on Ligandand Voltage-gated $\mathrm{Ca}^{2+}$ Release

Indo-1 $\mathrm{Ca}^{2+}$ measurements in intact myotubes (Fig. 6) and whole-cell voltage clamp (Fig. 7 and Table I) experiments were also conducted in myotubes expressing each of the single $\left(\Delta \mathrm{M}_{1}, \Delta \mathrm{M}_{2}\right.$, and $\left.\Delta \mathrm{M}_{3}\right)$ and double $\left(\Delta \mathrm{M}_{1,2}, \Delta \mathrm{M}_{2,3}\right.$, and $\left.\Delta \mathrm{M}_{1,3}\right)$ RyR1 mutations. Electrically evoked release (Fig. 6 A), ligand-induced release (Fig. 6 , B-D), and both retrograde (Fig. $7 \mathrm{~A}$ and Table I) and orthograde coupling (Fig. $7 \mathrm{~B}$ and Table I) were not significantly different between WT RyR1-expressing myotubes and either $\Delta \mathrm{M}_{1^{-}}, \Delta \mathrm{M}_{2^{-}}, \Delta \mathrm{M}_{3^{-}}$, or $\Delta \mathrm{M}_{1,3^{-}}$expressing myotubes. On the other hand, effects of the $\Delta \mathrm{M}_{2,3}$ mutation were similar to those of $\Delta \mathrm{M}_{1,2,3}$ in that $\Delta \mathrm{M}_{2,3^{-}}$ expressing myotubes also lacked electrically evoked $\mathrm{Ca}^{2+}$ release (Fig. 6 A), exhibited slowed kinetics of caffeineinduced $\mathrm{Ca}^{2+}$ release (Fig. 6, C and D), normal L-type $\mathrm{Ca}^{2+}$ channel activity (Fig. $7 \mathrm{~A}$ and Table I), and lacked sigmoidal voltage-gated $\mathrm{Ca}^{2+}$ release (Fig. $7 \mathrm{~B}$ ). Interestingly, reduced triadin binding to the $\Delta \mathrm{M}_{1,2}$ mutant (Fig. $1 \mathrm{~B})$ was accompanied by a significant reduction in the magnitude of electrically evoked $\mathrm{Ca}^{2+}$ release (Fig. $6 \mathrm{~A}$ ) and a slowing in ligand-induced $\mathrm{Ca}^{2+}$ release (Fig. 6, $\mathrm{C}$ and $\mathrm{D})$. In patch clamp experiments, there was a tendency $(\mathrm{P}=0.05)$ for a reduction in voltage-gated $\mathrm{Ca}^{2+}$ release measured at the end of 200-ms depolarizations in $\Delta \mathrm{M}_{1,2}$-expressing myotubes (Table I). However, for release assessed $30 \mathrm{~ms}$ after the start of the test pulse (to approximate release during a brief action potential), voltage-gated $\mathrm{Ca}^{2+}$ release (Fig. $7 \mathrm{C}$ and Table I) and the maximum rate of $\mathrm{Ca}^{2+}$ release (Fig. $7 \mathrm{D}$ ), approximated from the peak of the first derivative of the $\mathrm{Ca}^{2+}$ transient elicited at $+70 \mathrm{mV}(\delta(\Delta \mathrm{F} / \mathrm{F}) / \delta \mathrm{t})$, were significantly $(\mathrm{P}<$ $0.01)$ reduced in $\Delta \mathrm{M}_{1,2}$-expressing myotubes.

Triadin Binding-deficient RyR1 Mutants Exhibit Normal Junctional Targeting

The reduction in voltage-gated $\mathrm{Ca}^{2+}$ release documented in $\Delta \mathrm{M}_{1,2^{-}}, \Delta \mathrm{M}_{2,3^{-}}$, and $\Delta \mathrm{M}_{1,2,3^{-}}$expressing myotubes (Fig. 7, B and C) could result from a lack of proper targeting 

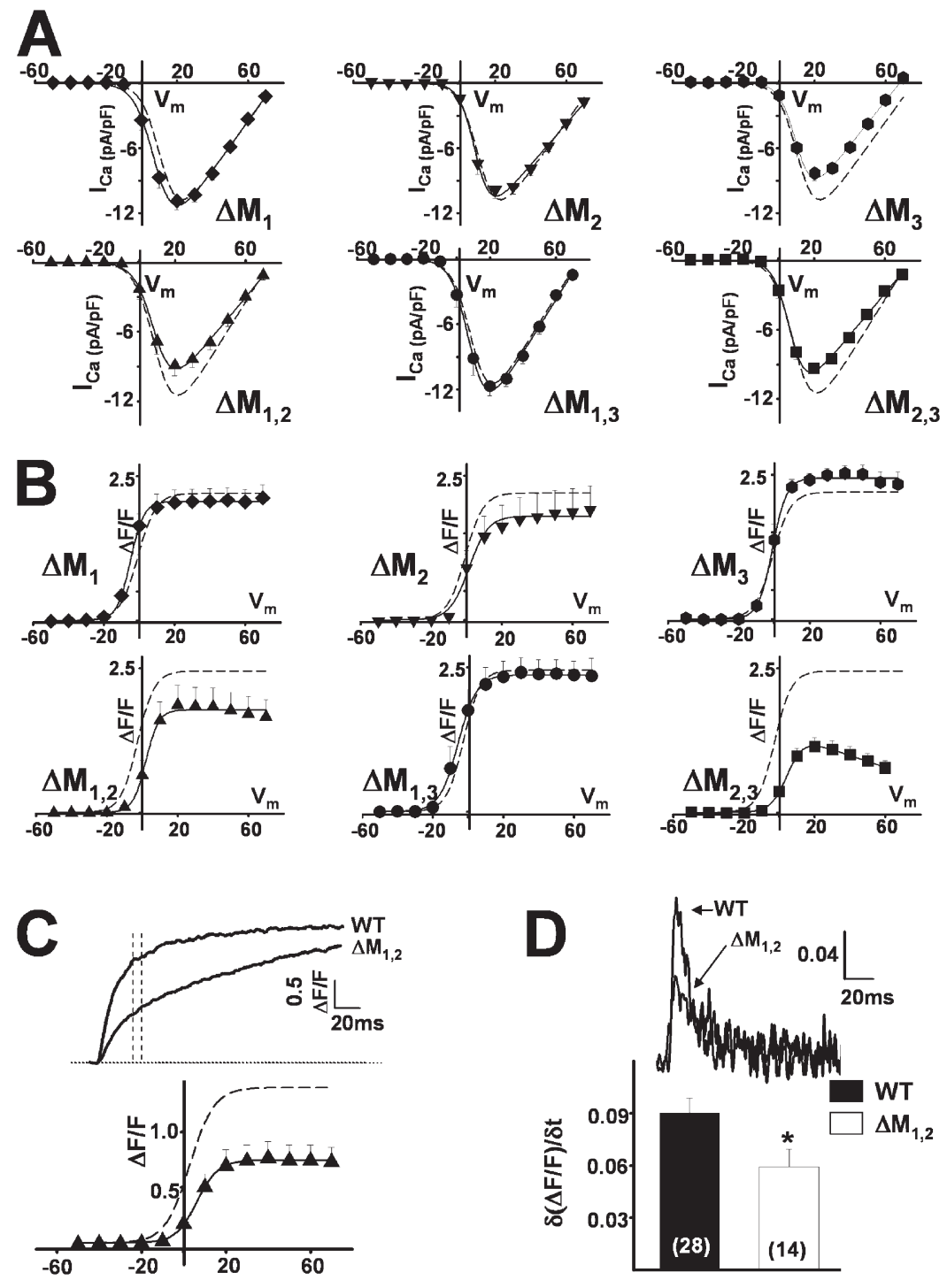

Figure 7. Effects of the terminal luminal loop RyR1 mutants on orthograde and retrograde coupling. (A and B) Average voltage dependence of L-type $\mathrm{Ca}^{2+}$ current density (A) and depolarization-induced $\mathrm{Ca}^{2+}$ transients (B) in $\Delta \mathrm{M}_{1^{-}}, \Delta \mathrm{M}_{2^{-}}$, $\Delta \mathrm{M}_{3^{-}}, \Delta \mathrm{M}_{1,2^{-}}, \Delta \mathrm{M}_{1,3^{-}}$, and $\Delta \mathrm{M}_{2,3^{3}}$ expressing myotubes. Dashed lines representing the average voltage dependence obtained from WT-expressing myotubes are shown for comparison. (C) Representative depolarization-induced (test potential $=$ $+70 \mathrm{mV}$ ) $\mathrm{Ca}^{2+}$ transients from WT RyR1- and $\Delta \mathrm{M}_{1,2}$-expressing myotubes (top). Voltage dependence of $\mathrm{Ca}^{2+}$ transients measured $30 \mathrm{~ms}$ after the start of the test pulse (bottom). (D) Differentials of fluorescence traces $(+70 \mathrm{mV})$ taken during the initial phase of depolarization (top). Bar graph of average peak differential $(\delta(\Delta \mathrm{F} / \mathrm{F}) / \delta \mathrm{t})$ (bottom). The number of experiments is given within each bar. *, $\mathrm{P}<0.01$.

of the mutant release channels to DHPR-containing SR-sarcolemmal junctions. However, our finding that all three of these triadin binding-deficient mutant RyR1 channels restored retrograde DHPR $\mathrm{Ca}^{2+}$ channel conductance to a similar degree as WT RyR1 (Fig. 6 A and Table I) provides strong functional evidence that each mutant was expressed, properly targeted to SR-sarcolemmal junctions, and interacted with DHPRs present in the junction. Nevertheless, we also compared DHPR and RyR subcellular localization in WT-, $\Delta \mathrm{M}_{1,2^{-}}, \Delta \mathrm{M}_{2,3^{-}}$, and $\Delta \mathrm{M}_{1,2,3}$-expressing myotubes in coimmunofluorescence labeling experiments (Fig. 8). Consistent with the observed restoration of retrograde coupling for each of these constructs, the RyR1 mutants that displayed defects in triadin binding and electrically evoked $\mathrm{Ca}^{2+}$ release exhibited a punctate appearance (Fig. 8, left) that overlapped with discrete clusters of DHPR fluorescence (Fig. 8, middle). This similar punctate appearance indicates correct junctional targeting of each construct and is particularly evident in the merged images (Fig. 8, right), in which green and red indicate RyR1 and DHPR, respectively, and yellow represents common regions of punctate appearance.

\section{DISCUSSION}

Since its initial discovery in 1990 (Brandt et al., 1990), triadin has been shown to be enriched and embedded in the SR membrane of the triad (Knudson et al., 1993a), to interact directly with both CSQ and RyR1 (Guo and Campbell, 1995), to inhibit RyR channels when applied to the cytoplasmic side (Ohkura et al., 1998), to activate channels when applied to the luminal side (Gyorke et al., 2004), and to contribute to the luminal $\mathrm{Ca}^{2+}$ transduction machinery that regulates $\mathrm{Ca}^{2+}$ release channel activity in skeletal muscle (Beard et al., 2004). Lee et al. (2004) identified three negatively charged amino acids (D4878, D4907, and E4908) in an RyR1 luminal loop that were each required for the isolated loop to bind a specific positively charged triadin KEKE motif (residues 
TABLE I

Parameters of Fitted IV and FV Curves

\begin{tabular}{|c|c|c|c|c|c|c|c|}
\hline & $G_{\max }$ & $k_{G}$ & $V_{G 1 / 2}$ & $V_{\text {rev }}$ & $(\Delta F / F)_{\max }$ & $k_{F}$ & $V_{F 1 / 2}$ \\
\hline & $n S / n F$ & $m V$ & $m V$ & $m V$ & & $m V$ & $m V$ \\
\hline RyR1 $(n=27)$ & $246 \pm 12$ & $4.8 \pm 0.2$ & $9.8 \pm 1.0$ & $74.6 \pm 1.5$ & $2.5 \pm 0.2$ & $4.8 \pm 0.3$ & $-2.7 \pm 0.9$ \\
\hline RyRl $(n=27)(30 \mathrm{~ms})$ & $175 \pm 10$ & $5.5 \pm 0.2$ & $12.0 \pm 1.0$ & $70.9 \pm 1.3$ & $1.4 \pm 0.1$ & $5.1 \pm 0.3$ & $2.7 \pm 0.9$ \\
\hline$\Delta \mathrm{M}_{1}(n=17)$ & $232 \pm 9$ & $4.7 \pm 0.5$ & $8.7 \pm 1.4$ & $74.5 \pm 1.7$ & $2.1 \pm 0.2$ & $3.6 \pm 0.5$ & $-5.1 \pm 0.9$ \\
\hline$\Delta \mathrm{M}_{2}(n=18)$ & $247 \pm 14$ & $5.0 \pm 0.4$ & $6.5 \pm 1.5$ & $75.7 \pm 2.1$ & $2.3 \pm 0.3$ & $4.2 \pm 0.5$ & $-2.0 \pm 1.8$ \\
\hline$\Delta \mathrm{M}_{3}(n=12)$ & $211 \pm 17$ & $4.6 \pm 0.3$ & $11.1 \pm 0.9$ & $68.6 \pm 1.8$ & $2.0 \pm 0.2$ & $3.6 \pm 0.3$ & $-2.4 \pm 0.7$ \\
\hline$\Delta \mathrm{M}_{1,2}(n=12)$ & $180 \pm 11$ & $4.5 \pm 0.3$ & $9.2 \pm 1.4$ & $76.6 \pm 2.3$ & $1.8 \pm 0.3$ & $2.9 \pm 0.3$ & $1.9 \pm 1.1$ \\
\hline$\Delta \mathrm{M}_{1,2}(n=12)(30 \mathrm{~ms})$ & $132 \pm 10$ & $5.7 \pm 0.2$ & $12.3 \pm 1.8$ & $70.3 \pm 2.0$ & $0.8 \pm 0.1^{\mathrm{b}}$ & $4.8 \pm 0.3$ & $7.0 \pm 1.1^{\mathrm{b}}$ \\
\hline$\Delta \mathrm{M}_{1,3}(n=6)$ & $259 \pm 14$ & $4.8 \pm 0.3$ & $8.9 \pm 1.0$ & $73.6 \pm 2.3$ & $2.4 \pm 0.3$ & $3.7 \pm 0.6$ & $-5.0 \pm 2.5$ \\
\hline$\Delta \mathrm{M}_{2,3}(n=17)$ & $187 \pm 8$ & $4.2 \pm 0.4$ & $6.9 \pm 1.2$ & $75.5 \pm 2.1$ & $0.9 \pm 0.1^{\mathrm{a}}$ & $3.4 \pm 0.3$ & $10.5 \pm 1.3^{\mathrm{a}}$ \\
\hline$\Delta \mathrm{M}_{1,2,3}(n=18)$ & $200 \pm 11$ & $3.6 \pm 0.2$ & $13.5 \pm 1.2$ & $75.0 \pm 2.0$ & $0.8 \pm 0.1^{\mathrm{a}}$ & $4.0 \pm 0.3$ & $4.3 \pm 1.1^{\mathrm{a}}$ \\
\hline
\end{tabular}

Values represent mean $\pm \mathrm{SEM}$ for $n$ experiments. Parameters for the voltage dependence of $\mathrm{Ca}^{2+}$ current $(I-V)$ and $\mathrm{Ca}^{2+}$ release $(\Delta F / F)$ were obtained by fitting myotubes within each group separately to the appropriate equation $(I-V$, Eq. $1 ; \Delta F / F$, Eqs. 2 and 3$)$ as described in Materials and methods. $G_{m a x}$, maximal L-channel conductance; $(\Delta F / F)_{\max }$, maximal change in relative fluo-4 fluorescence; $V_{\text {rev }}$, L-channel reversal potential; $V_{G 1 / 2}$ and $V_{F 1 / 2}$, potential at which $\mathrm{G}$ and $\mathrm{F}$ are half-maximal, respectively; $k_{G}$ and $k_{F}$, slope factors for $I-V$ and $\Delta F / F$, respectively.

ap $<0.01$, compared to WT $(200 \mathrm{~ms})$.

bP $<0.01$, compared to WT $(30 \mathrm{~ms})$.

200-232) (Fig. 1 A). Our results provide the following important and novel contributions with regard to triadin binding/regulation of RyR1: (a) a single mutation to any of these three negatively charged residues is not sufficient to modify RyR1-triadin association and the combination of the different mutations demonstrates that each residue contributes unequally (D4907 > E4908 $>$ D4878) to triadin binding (Fig. 1 B), (b) the RyR1 luminal loop mutations do not directly alter release channel function (Figs. 4 and 5), (c) luminal loop mutations that disrupt triadin binding do not alter either junctin binding (Fig. 1 C) or RyR1 junctional targeting (Fig. 8), and (d) triadin binding to RyR1 ensures rapid and robust $\mathrm{Ca}^{2+}$ release during both voltage- and ligand-induced activation (Figs. 2, 3, 6, and 7; and Table I).

Recently, Lee et al. (2006) found that triadin binding was reduced and the kinetics of caffeine-induced calcium release slowed following infection of RyR-null 1B5 myotubes with herpes simplex virus-1 virions packaged with either $\Delta \mathrm{M}_{2}$ or $\Delta \mathrm{M}_{1,2,3}$ compared with that observed for WT RyR1 (Lee et al., 2006). We found a similar slowing in the kinetics of caffeine-induced calcium release in $\Delta \mathrm{M}_{1,2,3}$-expressing primary dyspedic myotubes (Fig. $2 \mathrm{C}$ ). However, unlike Lee et al. (2006), we found that triadin binding to RyR1 as well as the kinetics of caffeineinduced calcium release were unaltered by the $\Delta \mathrm{M}_{2}$ mutation (Fig. 6, C and D). Differences between the two studies observed for the effects of the $\Delta \mathrm{M}_{2}$ mutation are not entirely clear, but may involve differences between the cells, expression methods, and biochemical/analytical approaches used in the two studies.

Importantly, results presented here are the first to characterize the impact of triadin binding to RyR1 on the orthograde and retrograde signals of EC coupling. Specifically, we found that triadin binding to RyR1 en- hances release channel activity during both voltage and ligand activation and that this critical regulation of release channel activity ensures robust and rapid calcium release during skeletal muscle EC coupling. This idea is further supported by our observation that $\left[{ }^{3} \mathrm{H}\right]$ ryanodine binding to WT RyR1, but not $\Delta \mathrm{M}_{1,2,3}$, is significantly enhanced by the addition of purified triadin (Fig. 5 B) and that triadin increases the open probability of RyR channels incorporated into planar lipid bilayers (Gyorke et al., 2004). In addition, our study is also the first to demonstrate that the mutations in RyR1 used to disrupt triadin binding do not directly affect release channel activity, retrograde RyR1-DHPR signaling, or the ability of junctin to bind to RyR1.

Defects observed for the RyR1 mutants could result either from effects of the mutations on triadin binding, direct effects on the channel, or both. We show that these mutations do not directly affect RyR1 channel function; WT and $\Delta \mathrm{M}_{1,2,3}$ channels expressed in HEK293 cells exhibited similar $\mathrm{Ca}^{2+}$ dependence of $\left[{ }^{3} \mathrm{H}\right]$ ryanodine binding (Fig. 5 A), open probability (Fig. 5, D and F), mean open (Fig. $5 \mathrm{G}$ ) and closed (Fig. $5 \mathrm{H}$ ) times, conductance (Fig. $5 \mathrm{~J}$ ), and $\mathrm{Ca}^{2+}$ release activity (Fig. 4, B-D). Moreover, purified triadin increased $\left[{ }^{3} \mathrm{H}\right]$ ryanodine binding to WT RyR1, but not to $\Delta \mathrm{M}_{1,2,3}$ (Fig. 5 B). In addition, WT RyR1 and triadin binding-deficient mutants expressed in dyspedic myotubes were activated by $\mathrm{Ca}^{2+}$ (Fig. 3 D), caffeine (Fig. 2 B), 4-cmc (Fig. 2 B), and fully restored retrograde DHPR coupling (Fig. $7 \mathrm{~A}$ and Table I). The slight reduction in maximal caffeine-induced $\mathrm{Ca}^{2+}$ release (Fig. $6 \mathrm{~B}$ ) observed for the triadin binding-deficient mutants may result from a combination of slow $\mathrm{Ca}^{2+}$ release inactivating some channels and the fact that triadin binding to RyR1 enhances $\mathrm{Ca}^{2+}$ gating (Fig. 5 B). Finally, effects of the luminal loop mutants on voltage-gated 

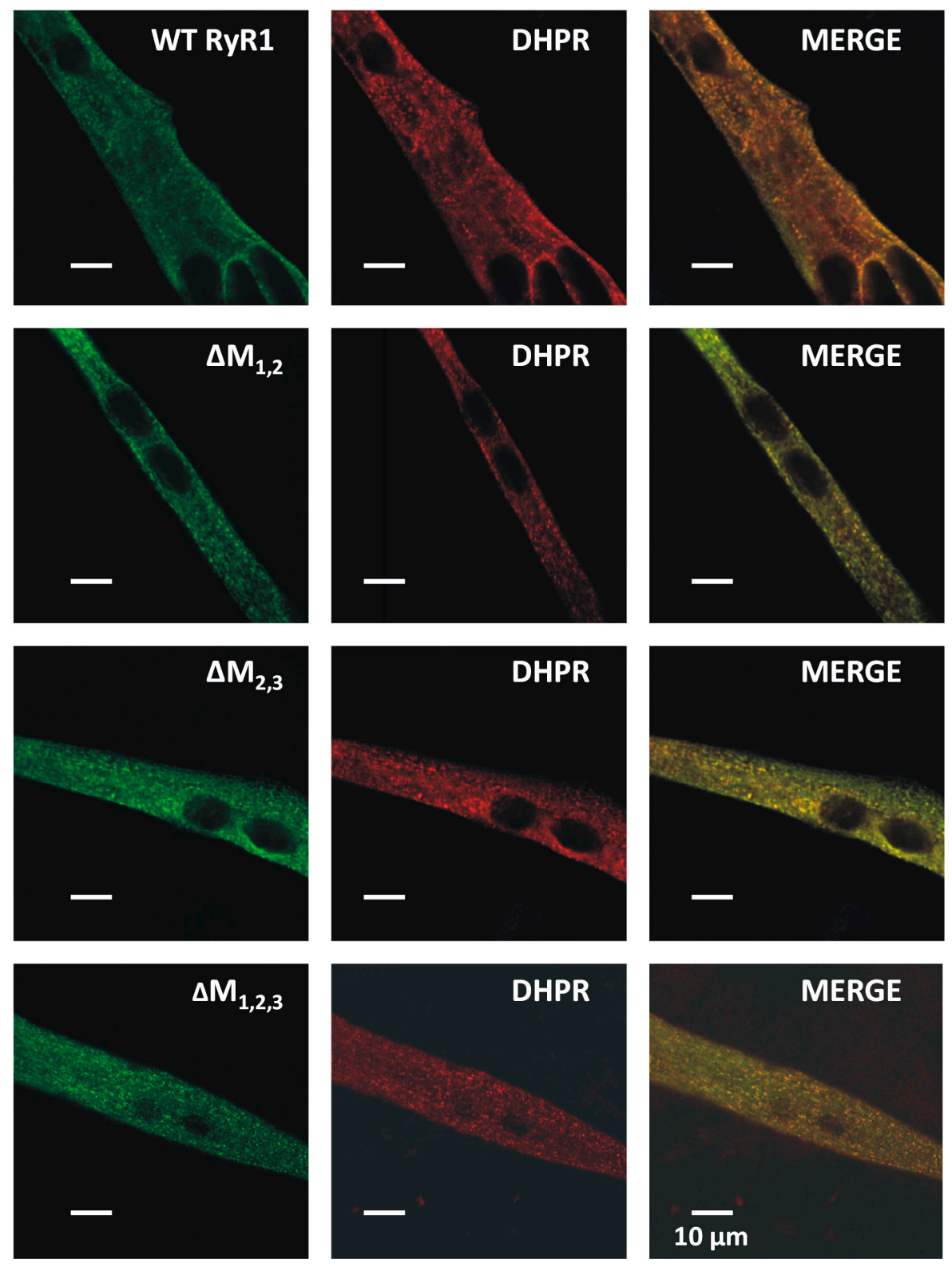

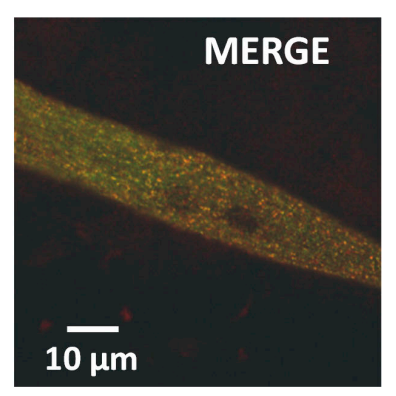

Figure 8. Triadin binding-deficient RyR1 mutants exhibit normal targeting to DHPR-containing junctions. (A) Double immunofluorescence labeling in representative WT- (first row), $\Delta \mathrm{M}_{1,2^{-}}$(second row), $\Delta \mathrm{M}_{2,3^{-}}$(third row), and $\Delta \mathrm{M}_{1,2,3^{-}}$ expressing (fourth row) myotubes with antibodies against RyR1 (left) and the DHPR (middle). The "merged images" (right) emphasize common regions of puncta (yellow foci) containing expressed RyR1 proteins and endogenous DHPRs in clusters that represent junctions of the SR with the sarcolemma.
$\mathrm{Ca}^{2+}$ release coincided perfectly with independent biochemical determination of triadin binding; mutations that did not affect binding $\left(\Delta \mathrm{M}_{1}, \Delta \mathrm{M}_{2}, \Delta \mathrm{M}_{3}\right.$, and $\left.\Delta \mathrm{M}_{1,3}\right)$ did not affect orthograde coupling, mutations that eliminated binding abolished orthograde coupling $\left(\Delta \mathrm{M}_{1,2,3}\right.$ and $\left.\Delta \mathrm{M}_{2,3}\right)$, and mutations that partially disrupted binding partially reduced orthograde coupling $\left(\Delta \mathrm{M}_{1,2}\right)$. Since the binding of purified triadin to purified WT or mutant RyR1 proteins in our experiments is likely to be thermodynamically different from in vivo binding that occurs in the SR, we cannot completely rule out the possibility that the effects of the RyR1 mutations on release and triadin binding are coincidentally related. Nevertheless, our results provide strong evidence that altered voltage- and ligand-induced $\mathrm{Ca}^{2+}$ release of the $\Delta \mathrm{M}_{1,2,3}, \Delta \mathrm{M}_{1,2}$, and $\Delta \mathrm{M}_{2,3}$ mutants result from defects in triadin binding rather than direct effects of the mutations on channel function.

Fig. 9 provides a simple model that ties together previously published results with the findings of this study. Under normal conditions (Fig. 9, left), triadin binds to both CSQ and the terminal luminal loop of RyR1, forming a quaternary complex along with junctin that maximizes $\mathrm{SR} \mathrm{Ca}^{2+}$ release following activation of RyR1 by either endogenous (e.g., DHPR) or exogenous (e.g., caffeine or 4-cmc) triggers. In this model, mutations in RyR1 that interfere with triadin binding are proposed to disrupt this critical RyR1 regulatory mechanism and result in the dissociation of the triadin-CSQ complex from the release channel (Fig. 9, right). Since we found that junctin binding to RyR1 is not affected by any of the RyR1 luminal loop mutations, a junctin-CSQ 


\section{Intact RyR1-Triadin Interaction}

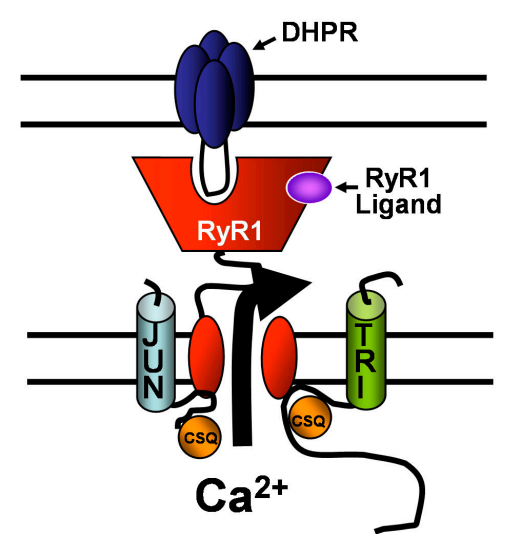

Disrupted RyR1-Triadin Interaction

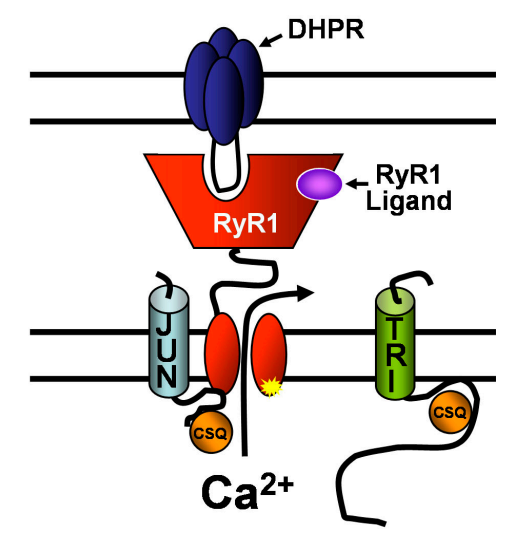

Figure 9. Proposed model for triadin regulation of DHPR and ligand activation of RyR1. The quaternary CSQ-triadin-RyR1-junctin interaction tethers CSQ close to the release channel pore and promotes high probability release channel opening (depicted by a large arrow) following either DHPR or ligand activation (left). Disruption of triadin binding to RyR1 results in a similar reduction in $\mathrm{SR} \mathrm{Ca}^{2+}$ release (depicted by a small arrow) following either DHPR or ligand activation (right). A junctin-CSQ complex is shown to bind to a separate RyR1 site from that of triadin. complex is shown to interact with an alternate RyR1 site in Fig. 9, suggesting that RyR1 activity may be differentially regulated by triadin-CSQ and junctin-CSQ. Our results indicate that triadin binding to RyR1 primes the channel for ligand/voltage sensor activation in order to ensure rapid $\mathrm{Ca}^{2+}$ release kinetics following either voltage- or ligand-induced activation. In the absence of this critical interaction of triadin-CSQ with RyR1, the kinetics of ligand- (Fig. $2 \mathrm{C}$ and Fig. $6 \mathrm{C}$ ) and voltage-induced (Fig. 7, C and D) $\mathrm{Ca}^{2+}$ release is markedly slowed. In the case of release stimulated by a brief action potential following neuromuscular transmission, this reduction in the rate of release is sufficient to essentially abolish $\mathrm{Ca}^{2+}$ release during EC coupling (Fig. 2 B and Fig. 6 A).

Overexpression of triadin in rat skeletal myotubes was shown to significantly reduce $\mathrm{KCl}$ depolarizationinduced $\mathrm{Ca}^{2+}$ release with minimal effects on either caffeine-/4-cmc-induced $\mathrm{Ca}^{2+}$ release or L-type $\mathrm{Ca}^{2+}$ current density (Rezgui et al., 2005). Triadin overexpression could result in either increased (due to enhanced levels of triadin) or decreased (due to overexpression causing triadin aggregation, Knudson et al., 1993a) triadin binding to RyR1. In either case, the results of Rezgui et al. (2005) indicate that the EC coupling machinery is exquisitely sensitive to triadin- RyR1 stoichiometry. Our results are consistent with this notion since disruption of triadin binding to RyR1 also markedly reduced orthograde, but not retrograde, DHPR-RyR1 coupling. The similar effects on voltage-gated $\mathrm{Ca}^{2+}$ release observed following triadin overexpression and triadin dissociation from RyR1 could be explained by effects either of disrupting triadin binding to RyR1 or of free triadin on the EC coupling machinery.

Preliminary reports have produced conflicting results regarding effects of triadin deficiency on EC coupling. For example, $\mathrm{KCl}-\mathrm{induced} \mathrm{Ca}^{2+}$ release is similar in myotubes derived from WT and pan-triadin knockout mice (Shen, X., J.R. Lopez, P.D. Allen, and C.F. Perez. 2006.
Biophysical Society Meeting. Abstr. 328) but significantly reduced and slowed following transient siRNAmediated knockdown of triadin and junctin in C2C12 myotubes (Wang, Y., L. Xinghai, H. Duan, T. Fulton, and G. Meissner. 2007. Biophysical Society Meeting. Abstr. 1237). The second finding is consistent with our results. The absence of an effect on depolarizationinduced $\mathrm{Ca}^{2+}$ release in pan-triadin knockout mice could result from a multitude of different compensatory mechanisms commandeered to correct for the loss of a critical RyR1 regulatory protein. In fact, skeletal muscle function and EC coupling is also not markedly altered following knockout of the skeletal muscle isoform of calsequestrin (CSQ1; Paolini et al., 2007). Similarly, cardiac SR Ca ${ }^{2+}$ storage and depolarization-induced $\mathrm{Ca}^{2+}$ release are essentially normal following either global knockout of CSQ2 (Knollmann et al., 2006) or cardiac-specific knockout of the $\mathrm{Na} / \mathrm{Ca}$ exchanger (Henderson et al., 2004), respectively. The surprising lack of an effect of genetic ablation of either CSQ1/2 or the $\mathrm{Na} / \mathrm{Ca}$ exchanger on EC coupling certainly does not mean that these proteins are not normally important for calcium storage and removal, respectively. Rather, remarkable compensatory changes in $\mathrm{Ca}^{2+}$ release unit assembly and efficiency were found to counteract $\mathrm{CSQ}$ and $\mathrm{Na} / \mathrm{Ca}$ exchange deficiency in these animals. Conceivably, similar compensatory changes might also account for the absence of a marked effect of triadin ablation of skeletal muscle EC coupling.

More than 15 different central core disease mutations in RyR1 have been identified in the terminal RyR1 luminal loop shown here to markedly influence triadin binding and ligand/voltage-gated $\mathrm{Ca}^{2+}$ release. A number of these mutations reduce $\mathrm{Ca}^{2+}$ release without significantly affecting either $\mathrm{SR} \mathrm{Ca}^{2+}$ content or retrograde coupling to the DHPR (Avila et al., 2003). Thus, it will be important for future studies to determine if any of these disease mutations in the RyR1 terminal luminal loop diminishes $\mathrm{Ca}^{2+}$ release 
during EC coupling by altering the critical regulatory interaction of triadin with the $\mathrm{SR} \mathrm{Ca}^{2+}$ release channel.

We would like to thank Dr. Paul D. Allen (Brigham and Women's Hospital, Harvard Medical School, Boston, MA) for providing access to the dyspedic mice used in this study and to Linda Groom for excellent technical assistance. The anti-junctin antibody used in this study was generously provided by Dr. Steve Cala (Wayne State University, Detroit, MI).

This work was supported by research grants from the National Institutes of Health (AR44657 to R.T. Dirksen) and the Australian National Health and Medical Research Council (316937 to A.F. Dulhunty).

Olaf S. Andersen served as editor.

Submitted: 23 March 2007

Accepted: 22 August 2007

\section{REFERENCES}

Avila, G., J.J. O'Brien, and R.T. Dirksen. 2001. Excitation-contraction uncoupling by a human central core disease mutation in the ryanodine receptor. Proc. Natl. Acad. Sci. USA. 98:4215-4220.

Avila, G., K.M. O'Connell, and R.T. Dirksen. 2003. The pore region of the skeletal muscle ryanodine receptor is a primary locus for excitation-contraction uncoupling in central core disease. J. Gen. Physiol. 121:277-286.

Beard, N.A., M.M. Sakowska, A.F. Dulhunty, and D.R. Laver. 2002. Calsequestrin is an inhibitor of skeletal muscle ryanodine receptor calcium release channels. Biophys. J. 82:310-320.

Beard, N.A., D.R. Laver, and A.F. Dulhunty. 2004. Calsequestrin and the calcium release channel of skeletal and cardiac muscle. Prog. Biophys. Mol. Biol. 85:33-69.

Beard, N.A., M.G. Casarotto, L. Wei, M. Varsanyi, D.R. Laver, and A.F. Dulhunty. 2005. Regulation of ryanodine receptors by calsequestrin: effect of high luminal $\mathrm{Ca}^{2+}$ and phosphorylation. Biophys. J. 88:3444-3454.

Brandt, N.R., A.H. Caswell, S.R. Wen, and J.A. Talvenheimo. 1990. Molecular interactions of the junctional foot protein and dihydropyridine receptor in skeletal muscle triads. J. Membr. Biol. 113:237-251.

Dirksen, R.T. 2002. Bi-directional coupling between dihydropyridine receptors and ryanodine receptors. Front. Biosci. 7:d659-d670.

Fessenden, J.D., Y. Wang, R.A. Moore, S.R. Chen, P.D. Allen, and I.N. Pessah. 2000. Divergent functional properties of ryanodine receptor types 1 and 3 expressed in a myogenic cell line. Biophys. J. 79:2509-2525.

Goonasekera, S.A., S.R. Chen, and R.T. Dirksen. 2005. Reconstitution of local $\mathrm{Ca}^{2+}$ signaling between cardiac L-type $\mathrm{Ca}^{2+}$ channels and ryanodine receptors: insights into regulation by FKBP12.6. Am. J. Physiol. Cell Physiol. 289:C1476-C1484.

Graves, T.K., and P.M. Hinkle. 2003. $\mathrm{Ca}^{2+}$-induced $\mathrm{Ca}^{2+}$ release in the pancreatic $\beta$-cell: direct evidence of endoplasmic reticulum $\mathrm{Ca}^{2+}$ release. Endocrinology. 144:3565-3574.

Groh, S., I. Marty, M. Ottolia, G. Prestipino, A. Chapel, M. Villaz, and M. Ronjat. 1999. Functional interaction of the cytoplasmic domain of triadin with the skeletal ryanodine receptor. J. Biol. Chem. 274:12278-12283.

Guo, W., and K.P. Campbell. 1995. Association of triadin with the ryanodine receptor and calsequestrin in the lumen of the sarcoplasmic reticulum. J. Biol. Chem. 270:9027-9030.

Gyorke, I., N. Hester, L.R. Jones, and S. Gyorke. 2004. The role of calsequestrin, triadin, and junctin in conferring cardiac ryanodine receptor responsiveness to luminal calcium. Biophys. J. 86:2121-2128.
Henderson, S.A., J.I. Goldhaber, J.M. So, T. Han, C. Motter, A. Ngo, C. Chantawansri, M.R. Ritter, M. Friedlander, D.A. Nicoll, et al. 2004. Functional adult myocardium in the absence of $\mathrm{Na}^{+}-\mathrm{Ca}^{2+}$ exchange: cardiac-specific knockout of NCX1. Circ. Res. 95:604-611.

Jiang, D., B. Xiao, L. Zhang, and S.R. Chen. 2002. Enhanced basal activity of a cardiac $\mathrm{Ca}^{2+}$ release channel (ryanodine receptor) mutant associated with ventricular tachycardia and sudden death. Circ. Res. 91:218-225.

Jones, L.R., L. Zhang, K. Sanborn, A.O. Jorgensen, and J. Kelley. 1995. Purification, primary structure, and immunological characterization of the 26-kDa calsequestrin binding protein (junctin) from cardiac junctional sarcoplasmic reticulum. J. Biol. Chem. 270:30787-30796.

Kim, K.C., A.H. Caswell, J.A. Talvenheimo, and N.R. Brandt. 1990. Isolation of a terminal cisterna protein which may link the dihydropyridine receptor to the junctional foot protein in skeletal muscle. Biochemistry. 29:9281-9289.

Kimura, T., M. Nakamori, J.D. Lueck, P. Pouliquin, F. Aoike, H. Fujimura, R.T. Dirksen, M.P. Takahashi, A.F. Dulhunty, and S. Sakoda. 2005. Altered mRNA splicing of the skeletal muscle ryanodine receptor and sarcoplasmic/endoplasmic reticulum $\mathrm{Ca}^{2+}$-ATPase in myotonic dystrophy type 1. Hum. Mol. Genet. 14:2189-2200.

Kimura, T., S.M. Pace, L. Wei, N.A. Beard, R.T. Dirksen, and A.F. Dulhunty. 2007. A variably spliced region in the type 1 ryanodine receptor may participate in an inter-domain interaction. Biochem. J. 401:317-324.

Knollmann, B.C., N. Chopra, T. Hlaing, B. Akin, T. Yang, K. Ettensohn, B.E. Knollmann, K.D. Horton, N.J. Weissman, I. Holinstat, et al. 2006. Casq2 deletion causes sarcoplasmic reticulum volume increase, premature $\mathrm{Ca}^{2+}$ release, and catecholaminergic polymorphic ventricular tachycardia. J. Clin. Invest. 116:2510-2520.

Knudson, C.M., K.K. Stang, A.O. Jorgensen, and K.P. Campbell. 1993a. Biochemical characterization of ultrastructural localization of a major junctional sarcoplasmic reticulum glycoprotein (triadin). J. Biol. Chem. 268:12637-12645.

Knudson, C.M., K.K. Stang, C.R. Moomaw, C.A. Slaughter, and K.P. Campbell. 1993b. Primary structure and topological analysis of a skeletal muscle-specific junctional sarcoplasmic reticulum glycoprotein (triadin). J. Biol. Chem. 268:12646-12654.

Laver, D.R., T.M. Baynes, and A.F. Dulhunty. 1997. Magnesium inhibition of ryanodine-receptor calcium channels: evidence for two independent mechanisms. J. Membr. Biol. 156:213-229.

Lee, E.H., D.W. Song, J.M. Lee, G. Meissner, P.D. Allen, and D.H. Kim. 2006. Occurrence of atypical $\mathrm{Ca}^{2+}$ transients in triadin-binding deficient-RYR1 mutants. Biochem. Biophys. Res. Commun. 351:909-914.

Lee, J.M., S.H. Rho, D.W. Shin, C. Cho, W.J. Park, S.H. Eom, J. Ma, and D.H. Kim. 2004. Negatively charged amino acids within the intraluminal loop of ryanodine receptor are involved in the interaction with triadin. J. Biol. Chem. 279:6994-7000.

Mulvey, C., and K. Ohlendieck. 2003. Use of continuous-elution gel electrophoresis as a preparative tool for blot overlay analysis. Anal. Biochem. 319:122-130.

Nakai, J., R.T. Dirksen, H.T. Nguyen, I.N. Pessah, K.G. Beam, and P.D. Allen. 1996. Enhanced dihydropyridine receptor channel activity in the presence of ryanodine receptor. Nature. 380:72-75.

Ohkura, M., K. Furukawa, H. Fujimori, A. Kuruma, S. Kawano, M. Hiraoka, A. Kuniyasu, H. Nakayama, and Y. Ohizumi. 1998. Dual regulation of the skeletal muscle ryanodine receptor by triadin and calsequestrin. Biochemistry. 37:12987-12993.

Paolini, C., M. Quarta, A. Nori, S. Boncompagni, M. Canato, P. Volpe, P.D. Allen, C. Reggiani, and F. Protasi. 2007. Re-organized stores and impaired calcium handling in skeletal muscle of mice lacking calsequestrin-1. J. Physiol. 10.1113/jphysiol.2007.138024.

Rezgui, S.S., S. Vassilopoulos, J. Brocard, J.C. Platel, A. Bouron, C. Arnoult, S. Oddoux, L. Garcia, M. De Waard, and I. Marty. 2005. 
Triadin (Trisk 95) overexpression blocks excitation-contraction coupling in rat skeletal myotubes. J. Biol. Chem. 280:39302-39308.

Rossi, A.E., and R.T. Dirksen. 2006. Sarcoplasmic reticulum: the dynamic calcium governor of muscle. Muscle Nerve. 33:715-731.

Sheridan, D.C., L. Carbonneau, C.A. Ahern, P. Nataraj, and R. Coronado. 2003. $\mathrm{Ca}^{2+}$-dependent excitation-contraction coupling triggered by the heterologous cardiac/brain DHPR $\beta 2 a-s u b u n i t$ in skeletal myotubes. Biophys. J. 85:3739-3757.

Tijskens, P., L.R. Jones, and C. Franzini-Armstrong. 2003. Junctin and calsequestrin overexpression in cardiac muscle: the role of junctin and the synthetic and delivery pathways for the two proteins. J. Mol. Cell. Cardiol. 35:961-974.

Wei, L., M. Varsanyi, A.F. Dulhunty, and N.A. Beard. 2006. The conformation of calsequestrin determines its ability to regulate skeletal ryanodine receptors. Biophys. J. 91:1288-1301.

Zhang, L., J. Kelley, G. Schmeisser, Y.M. Kobayashi, and L.R. Jones. 1997. Complex formation between junctin, triadin, calsequestrin, and the ryanodine receptor. Proteins of the cardiac junctional sarcoplasmic reticulum membrane. J. Biol. Chem. 272:23389-23397. 